\title{
The Impact of Tropospheric and Stratospheric Tropical Variability on the Location, Frequency, and Duration of Cool-Season Extratropical Synoptic Events $\mathscr{D}$
}

\author{
HANNAH E. ATtARD ${ }^{\mathrm{a}}$ AND ANDREA L. LANG \\ Department of Atmospheric and Environmental Sciences, University at Albany, State University of New York, Albany, New York
}

(Manuscript received 29 January 2018, in final form 21 November 2018)

\begin{abstract}
Cool-season occurrences of blocks, extratropical cyclones that undergo explosive cyclogenesis, and tropical cyclones (TCs) that undergo extratropical transition (ET) from 1980 to 2015 are analyzed using the National Aeronautics and Space Administration's Modern-Era Retrospective Analysis for Research and Applications, version 2, dataset. These synoptic events are first examined in a climatological analysis that includes identifying consecutive synoptic events, namely, blocks that follow bombs or ET events as well as extratropical cyclones that follow ET events. These synoptic events are then analyzed with respect to three tropical modes of variability: the Madden-Julian oscillation (MJO), El Niño-Southern Oscillation, and the stratospheric quasi-biennial oscillation (QBO). The QBO was considered from both a momentum and thermal point of view, using the equatorial 30-hPa zonal-mean wind and the equatorial zonal wind shear between 30 and $50 \mathrm{hPa}$, respectively. The results show that in the seven days prior to cool-season blocks and ET events, there is a statistically significant frequency minimum in MJO phases 7 and 3, respectively. With respect to the QBO, there is a statistically significant frequency maximum in neutral QBO conditions during bomb onset and a frequency minimum during ET onset. When stratifying bombs by latitude, there is a significant reduction in Arctic (i.e., poleward of $55^{\circ} \mathrm{N}$ ) bomb onset during easterly QBO conditions. The results show that both tropospheric and stratospheric tropical modes of variability can modulate the frequency of extratropical synoptic events to a similar degree.
\end{abstract}

\section{Introduction}

Extreme extratropical weather can occur in conjunction with a variety of synoptic-scale phenomena including rapidly deepening extratropical cyclones, persistent highamplitude ridges, and the extratropical transition (ET) of tropical cyclones (TCs). Extratropical cyclones that rapidly deepen are known as bombs and can bring hurricaneforce winds, heavy precipitation, and cold-air outbreaks to the extratropical regions (e.g., Sanders and Gyakum 1980; Bosart and Lin 1984; Kocin et al. 1995). Persistent highamplitude ridges, or blocks, prevent the normal eastward progression of synoptic-scale disturbances along the

Supplemental information related to this paper is available at the Journals Online website: https://doi.org/10.1175/MWR-D-180039.s1.

\footnotetext{
${ }^{a}$ Current affiliation: National Research Council/Space Science Division, Naval Research Laboratory, Washington, D.C.
}

Corresponding author: Andrea L. Lang, alang@albany.edu extratropical Rossby waveguide and are associated with anomalous meridional shifts in storm tracks (e.g., Nakamura and Wallace 1990). A TC is said to have undergone ET if it moves poleward, interacts with the extratropical flow, and acquires the baroclinic characteristics of an extratropical cyclone (Evans et al. 2017). Often, these posttropical cyclones maintain a link to tropical moisture and have the potential to substantially impact the midlatitude weather. Not only can bombs, blocks, and the ET of TCs produce hazardous weather locally, but they can also perturb the extratropical Rossby waveguide in such a way to produce nonlocal impacts. These nonlocal impacts include variability in both the tropospheric weather downstream (e.g., Archambault et al. 2013; Torn and Hakim 2015; Grams and Blumer 2015) and, in some instances, the stratospheric circulation (e.g., Martius et al. 2009; Colucci and Kelleher 2015; Coy and Pawson 2015).

Low-frequency variability, ranging from subseasonalto-seasonal time scales, can impact the distribution and frequency of the aforementioned synoptic events relative to climatology. For example, Gollan and Greatbatch (2017) 
suggest that the Madden-Julian oscillation (MJO), El Niño-Southern Oscillation (ENSO), and the oscillation of the sign of the equatorial upper-tropospheric zonalmean zonal wind, are each associated with different spatial distributions of blocking in the extratropical Northern Hemisphere. The mechanisms that explain these relationships are associated with teleconnections. For example, during enhanced phases of MJO equatorial convection, anticyclonic Rossby wave gyres form off the equator and to the west of the location of enhanced convection (Salby and Hendon 1994; Zhang 2005). The opposite occurs during suppressed phases of the MJOcyclonic Rossby wave gyres form to the west of the location of suppressed convection. These Rossby wave gyres can facilitate or suppress tropical-extratropical interaction and thus impact the extratropical flow on a global scale (e.g., Kiladis and Weickmann 1992; Higgins and Mo 1997; Matthews et al. 2004). Henderson et al. (2016) showed that all eight phases of the MJO are associated with robust differences in Northern Hemisphere distributions of blocking. The MJO can influence the extratropics to produce large-scale circulation anomalies, such as those represented by the Arctic Oscillation (e.g., L'Heureux and Higgins 2008) as well as impact synoptic flow regimes, including those favorable for U.S. tornado outbreaks (Thompson and Roundy 2013).

The tropical Pacific sea surface temperature variability explained by the phase of ENSO can also influence extratropical synoptic events. The impact of ENSO on the midlatitudes is well documented, from influencing the Pacific-North America pattern to shifting precipitation and temperature patterns across North America (e.g., Ropelewski and Halpert 1986; Trenberth et al. 1998). With respect to blocks, studies have suggested an increase in the frequency of Pacific blocking during La Niña years (Renwick and Wallace 1996; Wiedenmann et al. 2002). With respect to ET events, Wood and Ritchie (2014) concluded that in the east Pacific basin, ET events occur more frequently during periods of El Niño conditions, while Hart and Evans (2001) showed that the frequency of Atlantic ET events decreases during El Niño conditions.

The sign of the equatorial lower-stratospheric zonalmean zonal winds, largely described by the quasi-biennial oscillation (QBO; Baldwin et al. 2001), has been shown to influence the sign of the northern annular mode (e.g., Gray et al. 2018). During the easterly wind phase of the QBO, Northern Hemisphere polar cap heights are significantly higher and polar cap temperatures are significantly warmer. The QBO can also impact the midlatitude storm tracks and preferred regions of Rossby wave breaking (e.g., Holton and Tan 1980; Tinsley 1988; Labitzke and Loon 1989; Asbaghi et al. 2017; Wang et al. 2018).
The mechanisms that underpin these tropicalextratropical QBO relationships remain unclear (e.g., Garfinkel et al. 2012). Since the QBO describes stratospheric tropical variability, its relationship with the tropospheric extratropics has not been explored in the literature as thoroughly as the MJO and ENSO impacts on the extratropical weather.

Motivated by the high-impact nature of blocks, bombs, and ET events and their relationship with lowfrequency tropical variability, this study creates and analyzes climatological distributions of these synoptic events in a new reanalysis dataset: the National Aeronautics and Space Administration's (NASA) Modern-Era Retrospective Analysis for Research and Applications, version 2 (MERRA-2; Bosilovich et al. 2015). First, the distribution and frequency of the synoptic events in the MERRA-2 reanalysis dataset is presented to provide context for the subsequent analysis of the relationship between the synoptic events and tropical low-frequency variability.

The goal of this analysis is to answer the following research questions:

1) What is the climatological distribution of cool-season blocks, bombs, and ET events in the MERRA-2 dataset?

2) Do the phases of MJO, ENSO, and QBO influence the frequency of block-onset, bomb-onset, and ET days?

3) Is the influence of tropical stratospheric variability (e.g., the QBO) comparable to the influence of tropical tropospheric variability (e.g., the MJO and/ or ENSO) on the frequency and distribution of the identified sets of extratropical synoptic events?

The remainder of the paper is organized as follows: section 2 provides an overview of the datasets used and the methodologies employed for the creation of the case lists and statistical significance testing. Section 3 outlines the climatological distribution of the events and puts them into the context of the previous literature. Section 4 examines the statistical relationship between the tropical modes of variability and the extratropical synoptic events. Section 5 concludes with a summary and discussion of the analysis.

\section{Data and methods}

\section{a. Data}

The primary dataset used in this study is NASA's MERRA-2 dataset [Global Modeling and Assimilation Office (GMAO 2015)]. The MERRA-2 dataset is an updated version of the original MERRA dataset (Gelaro et al. 2017); for details on the upgrades to the MERRA-2 
TABLE 1. Phases of the MJO and corresponding convection locations as in Wheeler and Hendon (2004).

\begin{tabular}{ll}
\hline \hline Phase(s) & \multicolumn{1}{c}{ Location of convection } \\
\hline 1 & Western Hemisphere and Africa \\
2 and 3 & Indian Ocean \\
4 and 5 & Maritime Continent \\
6 and 7 & Western Pacific \\
8 & Western Hemisphere and Africa \\
\hline
\end{tabular}

from the original MERRA dataset the reader is directed to Rienecker et al. (2011). MERRA-2 has a horizontal resolution of $0.625^{\circ} \times 0.5^{\circ}$ and a vertical resolution of 72 levels up to $0.01 \mathrm{hPa}$. This study utilizes 6-hourly MERRA-2 data interpolated to pressure surfaces, of which there are 42 .

The case lists of blocks and bombs were created using the MERRA-2 dataset for the Northern Hemisphere cool season, defined as October-April, for the period of 1980-2015. The case list of ET events was obtained for the same period using the National Centers for Environmental Information's International Best Track Archive for Climate Stewardship (IBTrACS) data, version 3.7 (Knapp et al. 2010a, b). The cool season is used in this study to focus on the period when the extratropical waveguide is the most active.

The MJO (Madden and Julian 1971), which is characterized by an eastward-propagating center of convection near the equator with a period of about 30-60 days, is defined using the Real-time Multivariate MJO (RMM) index of Wheeler and Hendon (2004). Table 1 outlines the eight phases of the MJO from this index and their corresponding locations. The MJO phase and magnitude data were obtained from the Australian Bureau of Meteorology (www.bom.gov.au/climate/mjo). The phase and magnitude of the MJO can change on a daily basis and, via teleconnections, impact different regions of the extratropics at different lag periods, thus the analysis considers the MJO phase and magnitude over two 7-day periods prior to each date considered in the analysis. The first 7-day period is the week prior to each event date (i.e., lag days -7 to -1 ), hereafter $\mathrm{MJO}_{7 \mathrm{to1}}$. The second 7-day period is two weeks prior to each event date (i.e., lag days -14 to -8 ), hereafter $\mathrm{MJO}_{14 \mathrm{tos}}$. If the MJO amplitude, as defined by the $\mathrm{RMM}$ index in a 7-day period, was $<1$ more frequently than it was $>1$, then the MJO was characterized as "weak," otherwise the statistical mode of the MJO phase was used to define the phase of the MJO for the 7-day period. If two or more phases shared the mode, then the MJO phase for the 7-day period was defined as the modal phase with the largest MJO amplitude. Only the results from $\mathrm{MJO}_{7 \text { to1 }}$ will be shown as it had the most robust relationship with the extratropical synoptic events.
TABLE 2. Phases of ENSO based on Niño-3.4 SST anomaly.

\begin{tabular}{lc}
\hline \multicolumn{1}{c}{ Phase } & Niño-3.4 SST anomaly \\
\hline Strong La Niña & $T \leq-1.0^{\circ} \mathrm{C}$ \\
Weak La Niña & $-1.0^{\circ} \leq T<-0.5^{\circ} \mathrm{C}$ \\
Neutral & $-0.5^{\circ} \leq T<0.5^{\circ} \mathrm{C}$ \\
Weak El Niño & $0.5^{\circ} \leq T<1.0^{\circ} \mathrm{C}$ \\
Strong El Niño & $T \geq 1.0^{\circ} \mathrm{C}$ \\
\hline
\end{tabular}

ENSO describes the coupled atmosphere-ocean variability in the equatorial Pacific Ocean (e.g., Wang and Fiedler 2006). For this analysis the sea surface temperatures (SSTs) in the Niño-3.4 region, which is a box centered on the equator and $145^{\circ} \mathrm{W}$, was used to define the 5 phases of ENSO explored in this analysis (Table 2). SST anomalies $<-0.5^{\circ} \mathrm{C}$ correspond to La Niña conditions and SST anomalies $>0.5^{\circ} \mathrm{C}$ correspond to El Niño conditions. Niño- 3.4 data were obtained from the Climate Prediction Center (CPC; www.cpc.ncep.noaa.gov/ products/precip/CWlink/MJO/enso.shtml).

The QBO describes an oscillation in the sign of the zonal winds in the equatorial stratosphere, in which layers of easterlies or westerlies form first in the upper stratosphere then descend to the lower stratosphere with a period of about 28 months (Baldwin et al. 2001). This analysis considers the QBO from two perspectives. First, the equatorial zonal-mean wind at $30 \mathrm{hPa}$ was used to determine the phase of the QBO as westerly, neutral, or easterly. Second, phases of QBO vertical shear were defined as westerly, neutral, and easterly by the difference in the equatorial zonal-mean wind between 30 and $50 \mathrm{hPa}$. The QBO vertical shear is related, via the thermal wind relationship, to zonal-mean temperature anomalies that can have magnitudes up to $3 \mathrm{~K}$. The use of two QBO indices allows for the analysis to consider both the momentum (i.e., QBO index) and the thermal (i.e., QBO shear) anomalies associated with the $\mathrm{QBO}$. The QBO wind data were obtained from the CPC (www.cpc.ncep.noaa.gov/data/indices/). While there is no consistent vertical level or threshold used to quantify the QBO in the literature, this study defined the QBO and QBO-shear phase thresholds to obtain an approximately even distribution of dates between the three phases. Table 3 quantifies the phases of the QBO and the QBO-shear categories used in the analysis. Both sets of QBO phase definitions take into account the climatological differences in the magnitudes of easterly versus westerly shear layers.

\section{b. Synoptic event identification}

There are myriad ways blocks can be identified. Some methodologies use a one-dimensional criteria to identify "blocked" longitudes at a given latitude (e.g., 
TABle 3. Phases of the QBO.

\begin{tabular}{lcc}
\hline \hline Phase & 30-hPa zonal wind (QBO) & $\begin{array}{c}\text { 30-50-hPa zonal wind } \\
\text { shear (QBO shear) }\end{array}$ \\
\hline Easterly & $u \leq-7 \mathrm{~m} \mathrm{~s}^{-1}$ & $u_{z} \leq-8 \mathrm{~m} \mathrm{~s}^{-1}$ \\
Neutral & $-7<u \leq 7 \mathrm{~m} \mathrm{~s}^{-1}$ & $-8<u_{z} \leq 3 \mathrm{~m} \mathrm{~s}^{-1}$ \\
Westerly & $u>7 \mathrm{~m} \mathrm{~s}^{-1}$ & $u_{z}>3 \mathrm{~m} \mathrm{~s}^{-1}$ \\
\hline
\end{tabular}

Tibaldi and Molteni 1990, hereafter TM90; Pelly and Hoskins 2003) while others utilize a two-dimensional criteria to identify blocked regions at any latitude (e.g., Masato et al. 2013; Henderson et al. 2016). Blocks have also been identified using different variables to determine the blocked regions, including geopotential height (e.g., TM90; Barriopedro et al. 2006), and potential vorticity (PV; e.g., Pelly and Hoskins 2003; Schwierz et al. 2004; Berrisford et al. 2007). Though different numbers of blocks are identified with these different methodologies, the analyses consistently show block frequency maxima in the western North Pacific and Euro-Atlantic region.

For this analysis, blocks were identified following TM90, with some additional constraints motivated by other blocking definitions. The TM90 blocking identification methodology utilizes the 500-hPa geopotential height field and identifies instantaneous blocked longitudes by calculating the geopotential height gradient to the north (GHGN) and the geopotential height gradient to the south (GHGS) of specific latitudes, where GHGN and GHGS are defined as follows:

$$
\begin{aligned}
\text { GHGN } & =\frac{Z\left(\phi_{n}\right)-Z\left(\phi_{o}\right)}{\left(\phi_{n}-\phi_{o}\right)} \text { and } \\
\text { GHGS } & =\frac{Z\left(\phi_{o}\right)-Z\left(\phi_{s}\right)}{\left(\phi_{o}-\phi_{s}\right)} .
\end{aligned}
$$

In the above equations, $Z$ is the geopotential height and $\phi$ is latitude, where $\phi_{n}=80^{\circ} \mathrm{N}+\delta, \phi_{o}=60^{\circ} \mathrm{N}+\delta$, $\phi_{s}=40^{\circ} \mathrm{N}+\delta$, and $\delta=\left\{-4^{\circ}, 0^{\circ}, 4^{\circ}\right\}$. Blocks are thus identified at $56^{\circ}, 60^{\circ}$, and $64^{\circ} \mathrm{N}$ when the following two criteria are met: 1$)$ GHGS $>0 \mathrm{~m}\left({ }^{\circ} \text { latitude }\right)^{-1}$ and 2) GHGN $<-10 \mathrm{~m}$ ('latitude) ${ }^{-1}$.

Additional constraints were added to the TM90 blocking methodology to identify blocks that spanned multiple longitudes and existed for multiple days. Prior to applying the above criteria to the $500-\mathrm{hPa}$ geopotential height field, a 96-h centered mean was applied to the height field to follow the methods of the real-time blocking identification of the CPC (Climate Prediction Center 2006). The TM90 definition was then applied to this time-averaged height field yielding a list of dates, corresponding GHGS magnitudes, and blocked locations. Figure 1 shows the frequency distribution of blocked longitudes identified utilizing this methodology. Comparing this figure to

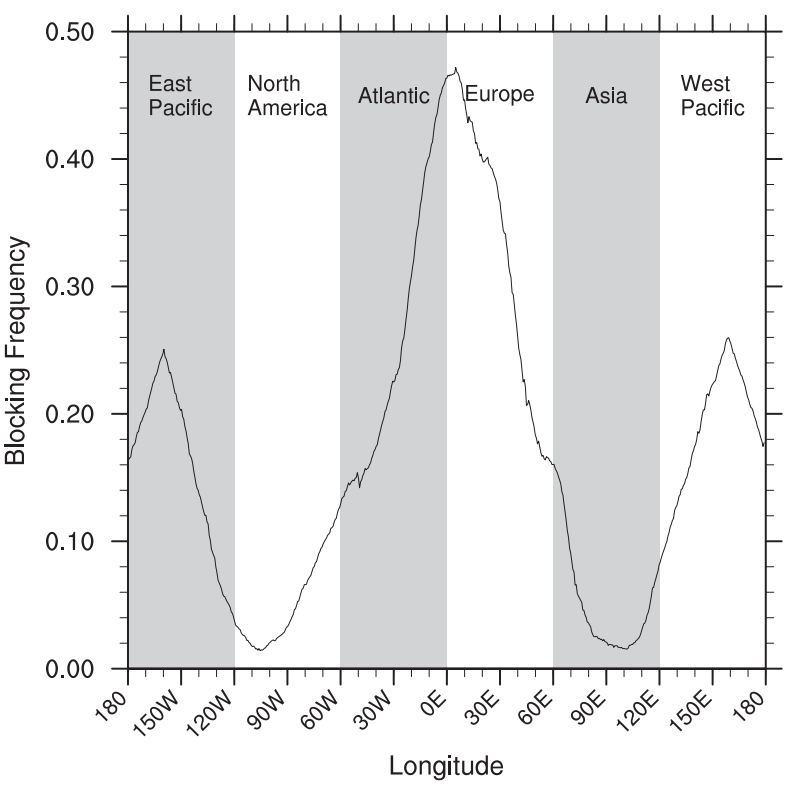

FIG. 1. The frequency of cool-season blocking longitudes identified with the TM90 blocking criteria in the MERRA-2 dataset. This figure is an updated version of Fig. 1 from TM90.

Fig. 1 in TM90, which shows the distribution of blocked longitudes from their seminal blocking analysis, shows a consistent pattern: there is a frequency maximum near $5^{\circ} \mathrm{E}$ in the Euro-Atlantic sector and two secondary maxima in the western and eastern Pacific basins at $160^{\circ} \mathrm{E}$ and $160^{\circ} \mathrm{W}$, respectively. Both distributions also show blocking minima near $100^{\circ} \mathrm{W} /{ }^{\circ} \mathrm{E}$. For background on the different blocking definitions that have been employed in the literature, the reader is directed to Barriopedro et al. (2010), which includes a comparison of different blocking definitions and explains that the TM90 blocking definition is a simple but strict algorithm, only retaining the most robust blocks.

To combine these discrete blocking locations into coherent events, blocks were defined as blocked longitudes that were identified at one latitude, spanned $\geq 20^{\circ}$ of continuous longitude, lasted $\geq 4$ days, and overlapped $\geq 10^{\circ}$ longitude at each time step. These criteria were based on previous studies, including TM90 (i.e., the 4-day duration threshold) and Pelly and Hoskins (2003, i.e., the $10^{\circ}$ overlapping threshold). The $20^{\circ}$ longitudinal expanse fits within the range of definitions used in previous studies that identified blocking events, which ranged from $12^{\circ}$ longitude (TM90) to $45^{\circ}$ longitude (Rex 1950). Blocks were then listed in order of magnitude according to their "strength," defined as the average GHGS value of all instantaneous locations included in the block event. Next, any block that occurred within 4 days and $60^{\circ}$ longitude of a "stronger" event was removed, where the longitude of the block was defined as the average 
longitude of all the instantaneous locations included in the block event. These thresholds were included to focus on the time and location of the maximum GHGS of blocks that spanned multiple latitudes. The first day a block was identified by these criteria is used as the block "onset" date in this analysis (i.e., $t_{0}$ ). The final blocking list, provided in dataset S1 of the online supplemental material, includes 288 events, the locations of which are outlined in Table 4.

Bombs were identified as rapidly deepening extratropical cyclones with sea level pressure (SLP) minima that decreased at least $24 \mathrm{hPa}$ in $24 \mathrm{~h}$ relative to $60^{\circ} \mathrm{N}$ (Sanders and Gyakum 1980) as follows:

$$
\frac{\mathrm{SLP}_{t_{+24 \mathrm{~h}}}-\mathrm{SLP}_{t_{0}}}{24 \mathrm{~h}} \times \frac{\sin \left(60^{\circ}\right)}{\sin \left(\frac{\text { lat }_{t_{+24 \mathrm{~h}}}-\mathrm{lat}_{t_{0}}}{2}\right)},
$$

where $t_{0}$ corresponds to $0000,0600,1200$, and 1800 UTC of every day included in the study and lat is the corresponding latitude of the cyclone center. To identify bombs, all extratropical cyclones that lasted $\geq 2$ days with track lengths $\geq 1000 \mathrm{~km}$ were identified using the extratropical cyclone tracking algorithm outlined in Hodges (1994, 1995). This algorithm uses spectral filtering to identify extratropical cyclones based on the SLP in the Northern Hemisphere. From the cyclones identified by the Hodges $(1994,1995)$ tracking algorithm, only cyclones that formed poleward of $30^{\circ} \mathrm{N}$ and were classified as bombs according to the above definition were retained. If a cyclone had multiple times when the bomb threshold was reached, the largest SLP decrease in $24 \mathrm{~h}$ was used to define the bomb's strength and to identify the bomb-onset time. The final case list, provided in dataset S2, includes 2852 bombs; the bomb locations are outlined in Table 4 .

A TC was identified as having undergone ET when the TC was identified as "extratropical" in the IBTrACS dataset and did not return to a "tropical" classification. The final list of events, provided in dataset S3, includes 151 ET events; the locations of these events are outlined in Table 4. Because of the focus of this paper on the cool season, which is offset from the peak TC season, the number of ET events included in this analysis is limited to the end of the Northern Hemisphere TC season.

The strength of each ET event was determined by quantifying its interaction with the extratropics, following Archambault et al. (2013). This strength metric is based on the 250-150-hPa layer-averaged negative PV advection by the irrotational wind, $-\mathbf{v}_{\chi} \cdot \nabla \mathrm{PV}$ in the vicinity of the ET event. By comparing the strongest versus the weakest cases, Archambault et al. (2013) showed that TCs associated with the most negative PV advection by the irrotational wind

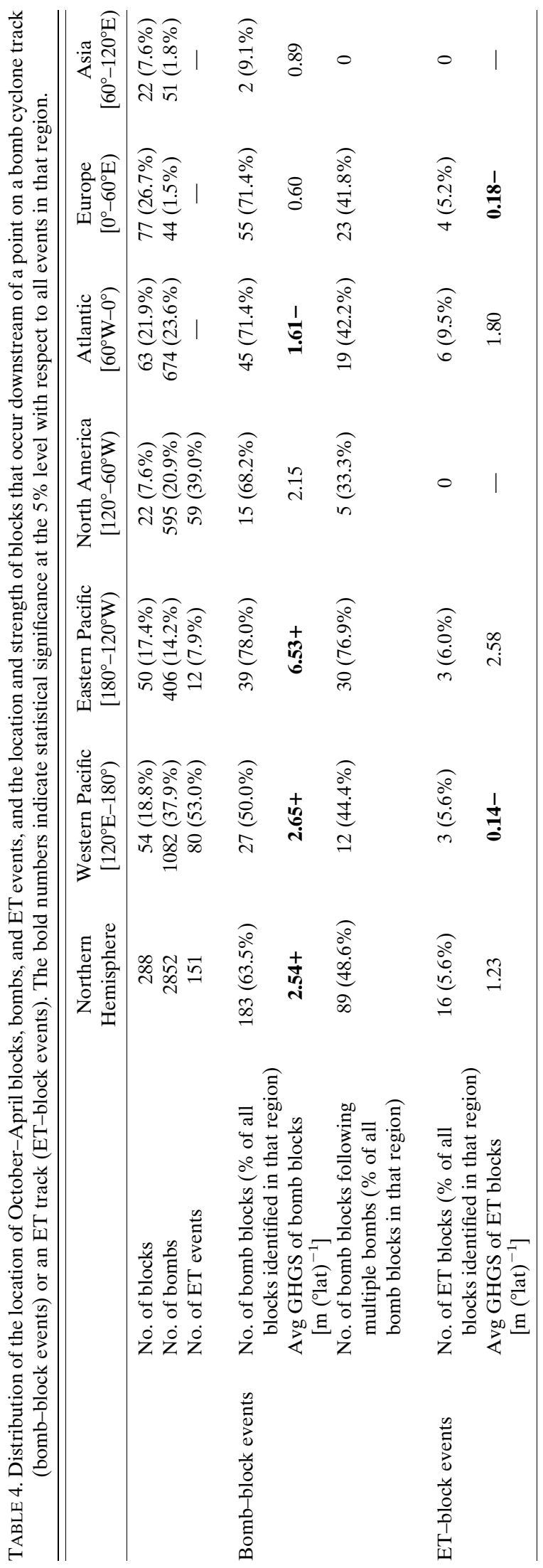


had a larger downstream impact on the extratropical flow. For consistency, the $250-150-\mathrm{hPa}$ layer is used in the Pacific and Atlantic basins, with the caveat that this layer best captures west Pacific TC outflow and is slightly higher than the average North Atlantic TC outflow layer. This study considers events classified as ET events and identifies the time of maximum interaction with respect to the time a TC was defined as extratropical in the IBTrACS dataset for TCs in the west Pacific, east Pacific, and Atlantic basins in the Northern Hemisphere. Following similar methods to Archambault et al. (2013), the location and time of maximum extratropical interaction for each ET event was identified within $\pm 96 \mathrm{~h}$ centered on the time of ET. This methodology differs from Archambault et al. (2013) as they looked for the maximum interaction with respect to the time of recurvature of the TC. The maximum extratropical interaction is defined as the most negative value of the PV advection by the irrotational wind within that 192 -h period. Each event was subjectively inspected to ensure that the time and location of maximum interaction with the extratropical flow was associated with the irrotational wind originating near the TC or its remnants (i.e., the cirrus shield associated with the TC or its remnants). Once the maximum extratropical interaction time and location were identified, the PV advection by the irrotational wind was spatially averaged over a $15^{\circ} \times 15^{\circ}$ box centered on the point of maximum interaction and temporally averaged over a 48 -h period centered on the time of maximum interaction (i.e., $t-24$ through $t+$ $24 \mathrm{~h}$ ). The result of this calculation is a metric with units of potential vorticity units per day (PVU; 1 PVU = $10^{-6} \mathrm{~K} \mathrm{~kg}^{-1} \mathrm{~m}^{2} \mathrm{~s}^{-1}$ ).

\section{c. Statistical significance testing}

Statistical significance was tested using bootstrap resampling to test the following: 1) the frequency distribution of the phases of the tropical modes of variability on synoptic event days with respect to all cool-season days, 2) the frequency of the phases of the tropical modes for synoptic events in particular regions with respect to all events, and 3 ) the characteristics of the individual synoptic events (e.g., block length or magnitude, bomb deepening rate or SLP minimum, etc.) by phase of tropical mode. Bootstrap resampling statistical significance testing was also utilized in consideration of the consecutive event lists such that statistical significance at the $5 \%$ level was tested by randomly choosing $n$ blocks from all blocks in a region without replacement, where $n$ is the number of consecutive blocking events in that region. This was repeated 10000 times to establish the $95 \%$ confidence of interval of the expected strength of bomb blocks in each region. If the bomb-block strength fell outside this confidence interval the strength is said to be statistically significant at the $5 \%$ level.

To explain the methodology for testing the statistical significance of the frequency distribution of tropical modes of variability on synoptic-event days with respect to all cool-season days (i.e., the Northern Hemisphere synoptic event frequencies analyzed in section 4), the method for testing the ENSO-block relationship is explained as an example. First, a subset of 288 (equal to the total number of identified blocks) cool-season days were randomly chosen from all cool-season days included in the study $(n=7428)$, without replacement. These 288 random days were then partitioned by ENSO phase and counted. This process was repeated 10000 times to establish the $95 \%$ confidence interval of the expected number of cool-season days in each ENSO phase for the given subset size. If the number of observed blocks in an ENSO phase was not within the expected $95 \%$ confidence interval of that ENSO phase, then the number of blocks in that phase is said to be statistically significant at the $5 \%$ level with respect to all cool-season days. This process was repeated for each synoptic event (i.e., blocks, bombs, and ET events) and each tropical mode of variability (i.e., MJO, ENSO, QBO, and QBO shear). For comparison across modes of variability, all numbers were converted to frequency in the analysis.

To explain the statistical significance testing methodology for events partitioned by location and tropical mode of variability, the methodology for testing the statistical significance of the relationship between the $\mathrm{MJO}_{7 \text { to } 1}$ and blocks that occurred between $90^{\circ} \mathrm{E}$ and $180^{\circ}$ $(n=64)$ is used as an example. First, a random sampling of 64 blocks was chosen from all 288 blocks. These 64 blocks were partitioned and counted by phase of the MJO. This was repeated 10000 times to establish the $95 \%$ confidence interval of the expected number of blocks in each phase. If the observed number of blocks in a phase and region was not within the $95 \%$ confidence interval of all blocks in that region for the given sample size, the observed number of blocks in that phase and region is said to be statistically significant at the $5 \%$ level with respect to all blocks.

Statistical significance for the characteristics of the synoptic event (e.g., block length, ET latitude, etc.) was calculated by randomly choosing the number of events in each tropical mode phase from all synoptic events of that type and calculating the $95 \%$ confidence interval of the characteristic.

\section{Climatological analysis}

\section{a. Blocks}

Of the 288 identified blocks, $77(26.7 \%)$ were in the European region and $63(21.9 \%)$ were in the Atlantic 

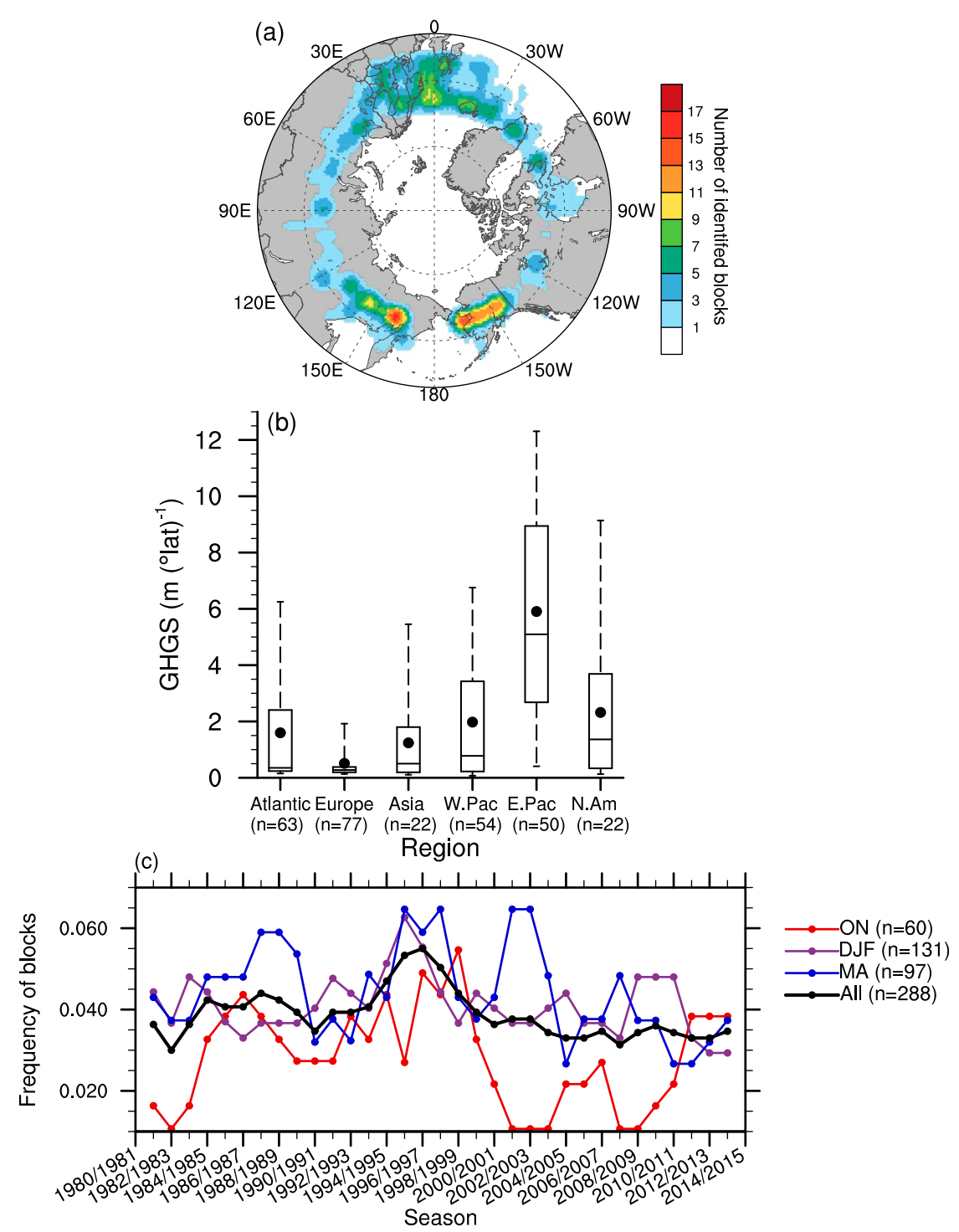

FIG. 2. (a) The density of the blocking events $(n=288)$ shown at the corresponding average longitude of blocks identified at $56^{\circ}, 60^{\circ}$, and $64^{\circ} \mathrm{N}$ (shaded) within $250 \mathrm{~km}$ of shaded region. (b) The distribution of the "strength" of blocks [i.e., the geopotential height gradient to the south of the blocked latitude (GHGS)] by region, where the 25th and 75th percentiles are represented by the bottom and top of the box, respectively, the 5th and 95th percentiles are represented by the whiskers, the median is represented by the center line, and the mean is represented by the black dot. The bounds of the regions used in the box-and-whisker plots correspond to those outlined in Table 4. (c) The interannual variability in the frequency of identified blocking events. A three-season running mean has been applied to the data thus the first (1980/81) and last (2014/15) seasons are not plotted. Frequency is defined by dividing the number of identified blocks by number of: cool-season days (black), October-November days (red), December-January-February days (purple), or March-April days (blue) per season.

region (Table 4 and Fig. 2b), where the bounds for each region are outlined in Table 4. Together, the Europe and Atlantic regions contain $48.6 \%$ of all the identified blocks. Consistent with TM90, the Pacific sector contained two secondary maxima in blocking frequency, with $54(18.8 \%)$ and $50(17.4 \%)$ blocks identified in the western and eastern Pacific, respectively. The remaining $15 \%$ of the blocks are evenly distributed between North America and Asia (Table 4 and Fig. 2a). The latitude of blocks is unevenly distributed between basins. Blocks in the Euro-Atlantic sector were identified at all three blocking latitudes, but in the Pacific region, the vast 
majority of blocks were identified at the farthest north blocking latitude, $64^{\circ} \mathrm{N}$ (Fig. 2a).

Figure $2 b$ shows that Europe had, on average, the weakest blocks with a mean GHGS magnitude of $0.51 \mathrm{~m}$ ( ${ }^{\circ}$ latitude $)^{-1}$ and the 95 th percentile of the magnitude near $1.5 \mathrm{~m}$ ( ${ }^{\circ}$ latitude $)^{-1}$. The Atlantic sector however, had a mean GHGS magnitude of $1.6 \mathrm{~m}$ ( ${ }^{\circ}$ latitude) $)^{-1}$ with the 95th percentile of the magnitude nearing $6.0 \mathrm{~m}$ ('latitude) $)^{-1}$. The blocks identified in the western and eastern Pacific basins accounted for the strongest blocks, with mean GHGS magnitudes of $1.98 \mathrm{~m}$ ( ${ }^{\circ}$ latitude) ${ }^{-1}$ and $5.91 \mathrm{~m}$ ( ${ }^{\circ}$ latitude) ${ }^{-1}$, respectively. These different mean magnitudes by location show that, on average, blocks that occur in Europe are the weakest of all regions.

With respect to the interseasonal variability of blocks, the 1996/97 season had the largest frequency of identified blocks ( 0.05 blocks day $^{-1}$ ) while the $1982 / 83$ season had the smallest frequency of identified blocks $(0.024$ blocks day ${ }^{-1}$; Fig. 2c). A 3-yr running mean has been applied to the data to smooth out differences associated with the large-scale variability (e.g., tropical interannual variability). The smoothed data were used to calculate a trend in the cool-season blocking frequency, which was negative but not statistically significant $\left(r^{2}\right.$ value $\left.=0.08\right)$. This lack of an interannual trend in blocking frequency is consistent with Barnes et al. (2014) who also showed that there was no significant trend in blocking frequency regardless of blocking index employed. The largest subseasonal frequency of blocks occurred in March and April ( 0.045 blocks day $\left.^{-1}\right)$ closely followed by December, January, and February (0.041 blocks day ${ }^{-1}$; Fig. 2c). October and November had a notably smaller frequency of blocks, 0.028 blocks day $^{-1}$, than the other subseason categories. The interannual variability of each coolseason subseason category does not show a trend with time, although, there is a notable October and November minima in the frequency of blocking events in from the late 1990s to the late 2000s (Fig. 2c). This early season blocking minima in the mid-1990s is compensated by blocking frequency maxima in the Pacific, North America, and Asia (i.e., approximately $20 \%$ of all blocks identified in each region; not shown) from December to April (Fig. 2c).

\section{b. Bombs}

Bombs climatologically occur on the poleward side of the storm track in the western ocean basins, with a secondary maximum in the exit region of the storm track (e.g., Sanders and Gyakum 1980; Roebber 1984; Chen et al. 1992; Lim and Simmonds 2002). Consistent with prior research, the largest number of bombs identified in this study was in the west Pacific region, which accounted for $1082(37.9 \%)$ of the 2852 identified bombs (Table 4; Figs. 3a,b). A secondary bomb maximum was located in the Atlantic, which accounted for 674 (23.6\%) of the 2852 identified bombs (Table 4). This distribution is consistent with Sanders and Gyakum (1980, their Fig. 3) who analyzed three winter seasons and also showed bomb frequency maxima in the western Pacific and Atlantic. In the Atlantic, the bomb-onset frequency maximum is located just off the coast of North America between $35^{\circ}$ and $45^{\circ} \mathrm{N}$, while the track frequency maximum is located to the northeast of the bomb-onset maximum, near $43^{\circ} \mathrm{N}$ and $65^{\circ} \mathrm{W}$ (Fig. 3a). The track frequency maximum then continues northeast, curving northward off the east coast of Greenland just west of $30^{\circ} \mathrm{W}$. The bombonset frequency maximum stays mainly to the south of the track frequency maximum, suggesting that cyclones that rapidly deepen over the western North Atlantic typically continue northeastward. There is a similar pattern in the west Pacific: the bomb-onset frequency is maximized off the east coast of Japan and the track frequency maximum continues northeastward, curving northward just before the date line (Fig. 3a).

As determined by the 24-h SLP change (i.e., bomb strength), the strongest bombs occurred in the Atlantic, west Pacific, and North American sectors, with a mean rates of SLP decrease of $34.4 \mathrm{hPa}(24 \mathrm{~h})^{-1}, 34.2 \mathrm{hPa}$ $(24 \mathrm{~h})^{-1}$, and $34.1 \mathrm{hPa}(24 \mathrm{~h})^{-1}$, respectively (Fig. 3b). These maxima were followed closely by east Pacific bombs, which has a mean rate of SLP decrease of $31.7 \mathrm{hPa}(24 \mathrm{~h})^{-1}$. This suggests that while the most explosive cyclogenesis typically occurs over water (i.e., the Pacific and Atlantic), explosive cyclogenesis of a similar magnitude frequently occurs in North America. Other than North America, the average bomb strength of each region is statistically significant at the $5 \%$ level with respect to a bootstrap resampling test of the same number of bombs in that region chosen from all identified bombs without replacement repeated 10000 times. The east Pacific, European, and Asian regions all have statistically significant smaller 24-h SLP decreases than expected. This suggests that the mean bomb strength in each region is statistically independent of all Northern Hemisphere cool-season bombs.

The interannual variability of Northern Hemisphere bomb frequency showed three seasons with the minimum number of identified bombs $\left(0.33\right.$ bombs day $\left.^{-1}\right)$ : 1983/84, 1994/95, 2008/09 (Fig. 3c). The 1999/2000 season had the largest number of identified bombs $\left(0.46\right.$ bombs day $\left.^{-1}\right)$. The smoothed data were used to calculate a trend in the cool-season bomb frequency, which was near zero and not statistically significant $\left(r^{2}\right.$ value of 0.0004). With respect to the intraseasonal variability, the highest frequency of bombs occurred in 


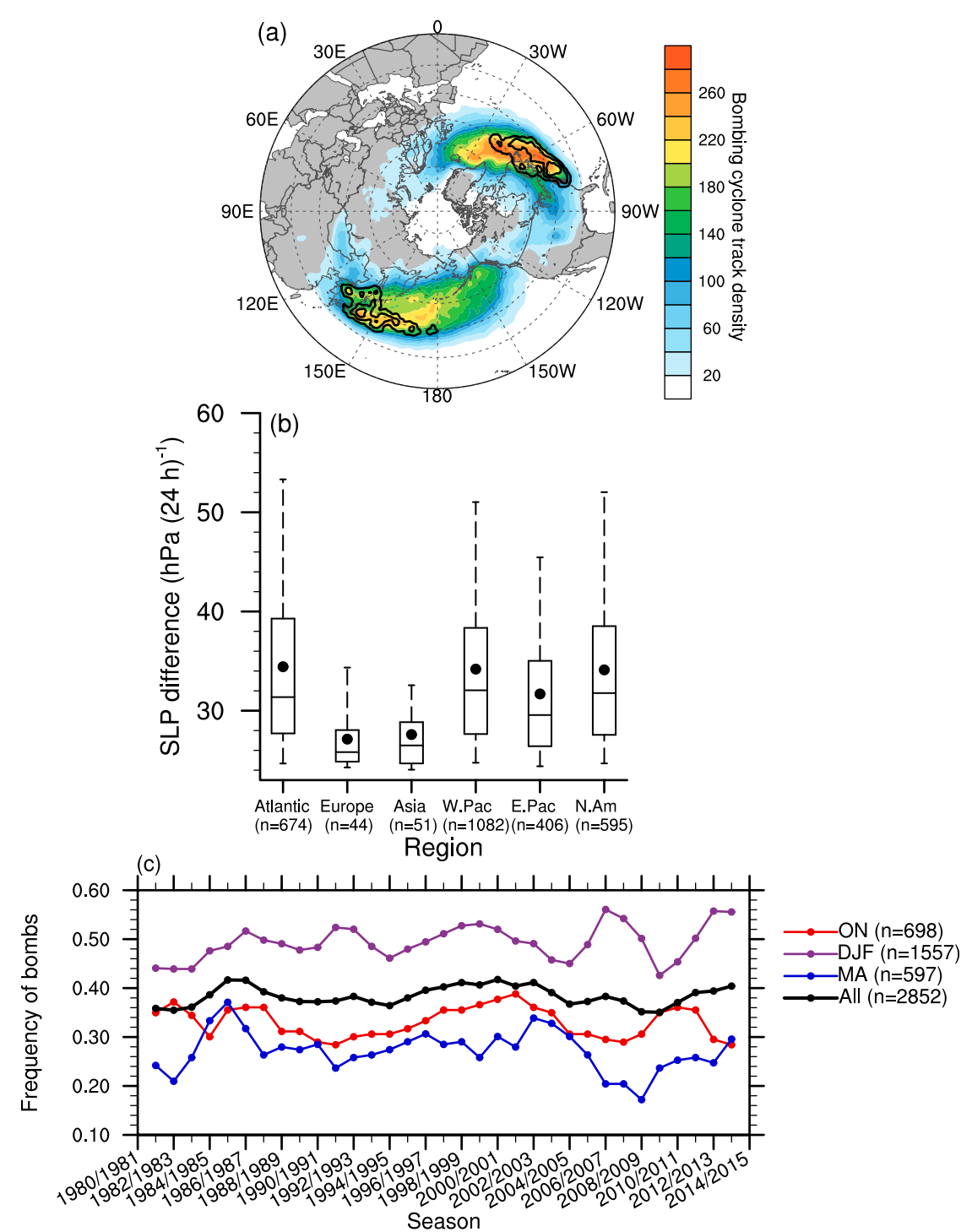

FIG. 3. As in Fig. 2, but in (a) for the tracks of cyclones that qualify as bombs $(n=2852$; shaded) and the density of bomb-onset location (black contours of $n=25,35$, and 45) and in (b) for the strength of bombs (i.e., the magnitude of 24-h SLP decrease).

December, January, and February (0.49 bombs day $^{-1}$; $n=1557)$ followed by October and November ( 0.33 bombs day $\left.^{-1} ; n=698\right)$ and then March and April (0.28 bombs day ${ }^{-1} ; n=597$; Fig. 3 c). This differs from the intraseasonal variability of blocking. While bombonset frequency has a maximum in the middle of the winter season (when the meridional temperature gradients are maximized), block-onset frequency is maximized during the transition from winter to summer (Figs. 2c and 3c).

\section{c. ET events}

Table 4 shows that over half of the cool-season ET events were identified in the western Pacific basin [i.e., $80(53 \%)$ of the 151$]$, while $59(39.1 \%)$ events were identified in the Atlantic basin and 12 (7.9\%) in the eastern Pacific. The spatial distribution of the TC tracks that underwent ET in the western Pacific suggests that most ET events recurve (i.e., there is a change in motion from westward to eastward) as the TC approaches Asia (Fig. 4a). These west Pacific ET events have a clear recurvature location between $120^{\circ}$ and $150^{\circ} \mathrm{E}$ near $20^{\circ} \mathrm{N}$, while the Atlantic TCs do not have a defined location of recurvature (Fig. 4a). The average strength of the west Pacific ET events (defined as the extratropical interaction metric) has the largest magnitude of all the basins with a value of -0.95 PVU day $^{-1}$ (Fig. 4b). ET events that occurred in the Atlantic and east Pacific had average extratropical interaction metrics of -0.58 


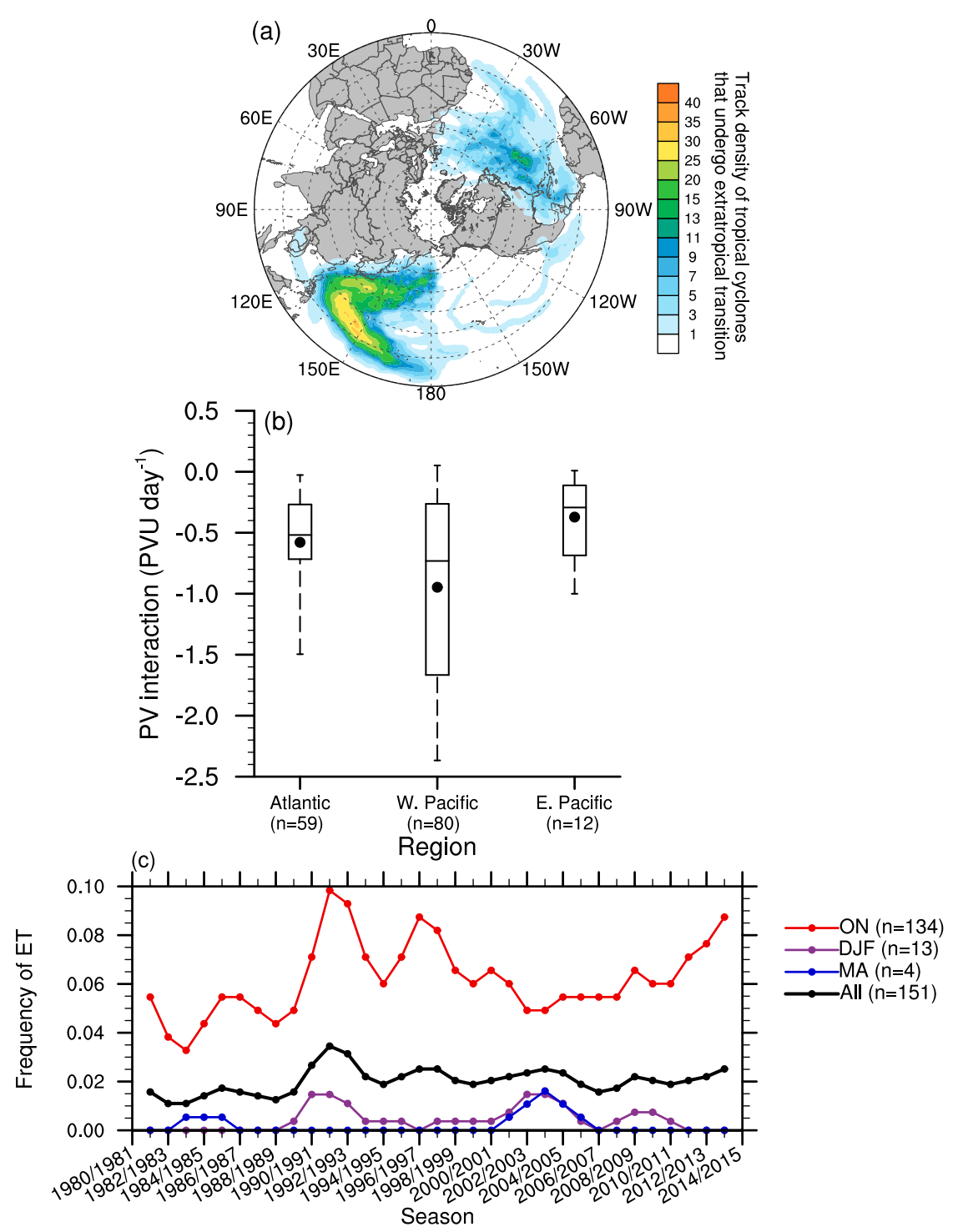

FIG. 4. As in Fig. 2, but in (a) for TC tracks that underwent ET $(n=151)$ and (b) the strength of ET events (i.e., the associated maximum extratropical interaction; the calculation is described in the text).

and $-0.37 \mathrm{PVU} \mathrm{day}^{-1}$, respectively (Fig. 4b). These differences in interaction metrics are also highlighted by the value of the 5 th percentile of the metric in each basin, which is approximately $-1.5 \mathrm{PVU} \mathrm{day}^{-1}$ for Atlantic ETs and nearly -2.4 PVU day $^{-1}$ for western Pacific ETs (Fig. 4b). Despite this study only analyzing cool-season ET and using a higher-resolution dataset, while Archambault et al. (2013) analyzed all recurving western North Pacific TCs, this range of west Pacific ET extratropical interaction is still consistent with Archambault et al. (2013). The range of the strongest extratropical interaction for recurving midlatitude TCs in Archambault et al. (2013) was between -1.62 and $-2.58 \mathrm{PVU} \mathrm{day}^{-1}$. The mean extratropical interaction for Atlantic and east Pacific ETs falls within range of the 20 recurving west Pacific TCs with the weakest extratropical interaction analyzed in Archambault et al. (2013), a result in part caused by the preferred lower outflow layer of Atlantic and east Pacific ETs. The values here are slightly weaker but consistent with Pantillon et al. (2015) who calculated the maximum midlatitude interaction of three North Atlantic ET events on the 330-K isentropic level.

Figure $4 \mathrm{c}$ is used to examine the interannual variability in Northern Hemisphere ET occurrence. The smallest number of identified cool-season ET events in a season was one, which occurred in both 1982/83 and 
1983/84, corresponding to a frequency of 0.01 ET events day ${ }^{-1}$. The most identified ET events in a season were nine, which occurred in the 1991/92 season, corresponding to a frequency of $0.03 \mathrm{ET}$ events day ${ }^{-1}$ (Fig. 4c). The smoothed data were used to calculate a trend in the cool-season ET frequency, which was positive but not statistically significant $\left(r^{2}=0.05\right)$. Unsurprisingly, the intraseasonal variability of ET events is dominated by October and November (0.063 ET events day $\left.{ }^{-1} ; n=134\right)$, with only 13 events in the December, January, and February (0.004 ET events day ${ }^{-1}$ ) and 4 events in March and April (0.002 ET events day ${ }^{-1}$; Fig. 4c). Interestingly, three out of the four ET events that occurred in March and April occurred between 2003 and 2005; two of these were west Pacific TCs, with one Atlantic TC (Ana in 2003).

\section{d. Blocks downstream of bomb and ET events}

Though blocks, bombs, and ET events have been primarily analyzed separately, a number of studies have also examined the coupled relationships between these synoptic phenomena. Lupo and Smith (1995) examined 63 blocking events and found that all were preceded by an identifiable surface cyclone, with 34 of the 63 blocks (59\%) preceded by cyclones that rapidly intensified as bombs. Their results suggested that the intensity of a block is correlated with the deepening rate (i.e., SLP decrease) of the precursor cyclone. Colucci and Alberta (1996) found that the planetary-scale midlatitude westerlies were weaker during periods of bombs followed by blocks compared to periods of blocks without a precursor bomb, suggesting that low-frequency variability may impact the bomb-block relationship. This portion of the analysis builds upon this previous literature by examining climatologies of several combinations of consecutive synoptic event types.

Of the 288 identified blocks, $183(63.5 \%)$ occurred within 5 days and $60^{\circ}$ downstream of a point on one of the 2852 bomb cyclone tracks (Table 4). These 183 blocking events are referred to as bomb blocks in this analysis. Of these 183 bomb blocks, $89(48.6 \%)$ followed more than one rapidly deepening cyclone (Table 4). Other than Asian blocks, west Pacific blocks had the lowest percentage of blocks with a preceding bomb (Table 4). Consistent with Lupo and Smith (1995), the strength of all Northern Hemisphere bomb blocks is statistically significantly stronger at the $5 \%$ level than a random sampling of all blocks, suggesting that blocks that follow a rapidly deepening cyclone are stronger than a random sampling of blocks. This relationship holds true for both west Pacific and east Pacific blocks but Atlantic bomb blocks are statistically significantly weak (Table 4).
The track frequency of the bombs associated with bomb blocks shows a maximum in the Atlantic sector to the southeast of Greenland (Fig. 5a), which is at the end of the track frequency maximum of all bombs (Fig. 3a). In the Pacific sector, the dominate track frequency maximum is located off the coast of Japan, collocated with the track frequency maximum of all bombs (Figs. 3a and 5a). There is a secondary track frequency maximum in the Bering Sea for bombs associated with bomb blocks (Fig. 5a). In the Euro-Atlantic sector blocks occur, on average, within $8^{\circ} \mathrm{N}$ of the average bomb cyclone track, with European blocks occurring, on average, only $3^{\circ} \mathrm{N}$ of the average bomb cyclone track (Fig. 5b). Atlantic blocks occur zonally closer to their upstream average bomb tracks (i.e., within $32^{\circ}$ ) than European blocks, which occur on average $41^{\circ}$ downstream of their average upstream bomb track. Pacific blocks occur, on average, farther north of their respective upstream bomb tracks than Euro-Atlantic blocks $\left(15^{\circ}\right.$ and $16^{\circ} \mathrm{N}$ for west and east Pacific bombs, respectively; Fig. 5b). West Pacific blocks, however, are zonally closer to their average upstream bomb tracks than Euro-Atlantic blocks, as west Pacific blocks are, on average, only $19^{\circ}$ downstream. This disparity in the meridional difference between Pacific bomb blocks and Euro-Atlantic bomb blocks and their associated upstream bomb tracks is attributed to both the blocking threshold used and the different latitudes of the bomb tracks between basins. The majority of west Pacific blocks were identified at the farthest north blocking latitude, $64^{\circ} \mathrm{N}$, while European blocks were identified at $56^{\circ}, 60^{\circ}$, and $64^{\circ} \mathrm{N}$. The west Pacific bomb track frequency maximum is located near $35^{\circ} \mathrm{N}$ while the Atlantic track frequency maximum is located near $50^{\circ} \mathrm{N}$ (Fig. 5a). Considering the block latitude and the bomb track frequency maximum together results in west Pacific blocks that are located farther north of their upstream bombs. There is also a zonal difference between regions, such that European and east Pacific blocks are located farther downstream of their average upstream bomb tracks than west Pacific and Atlantic blocks (Fig. 5b). This zonal disparity between regions is attributed to the preference for bombs to occur over water in the western basins, thus Atlantic and west Pacific blocks are zonally closer to their upstream bombs while east Pacific and European blocks are farther downstream from their upstream bombs. This disparity in the zonal difference between blocks and their upstream bombs by blocking location is consistent with Lupo and Smith (1995) who reported that bombs that preceded blocks typically occurred over ocean basins.

Using an idealized modeling study, Riemer et al. (2008) showed that an ET event can have downstream impacts including both downstream ridging and the 

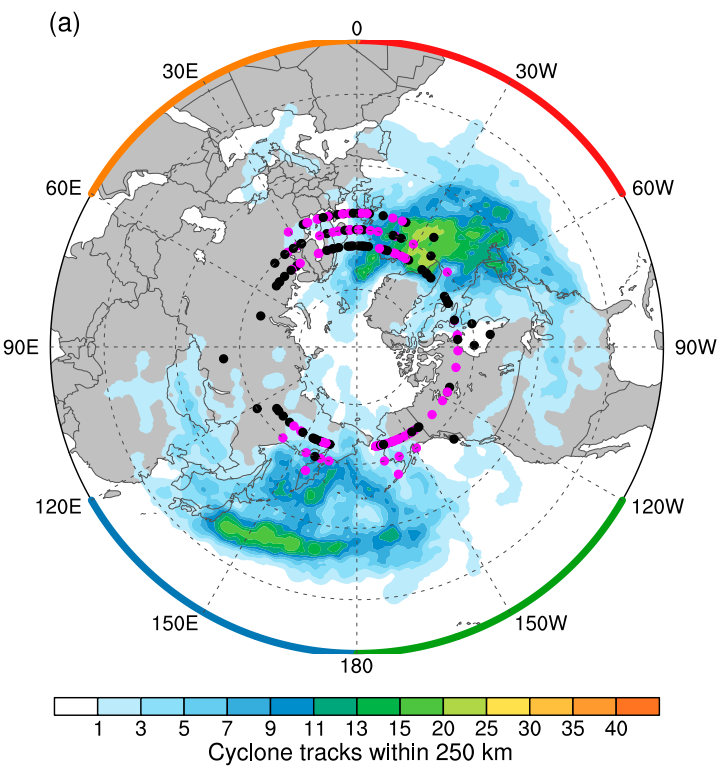

(b)

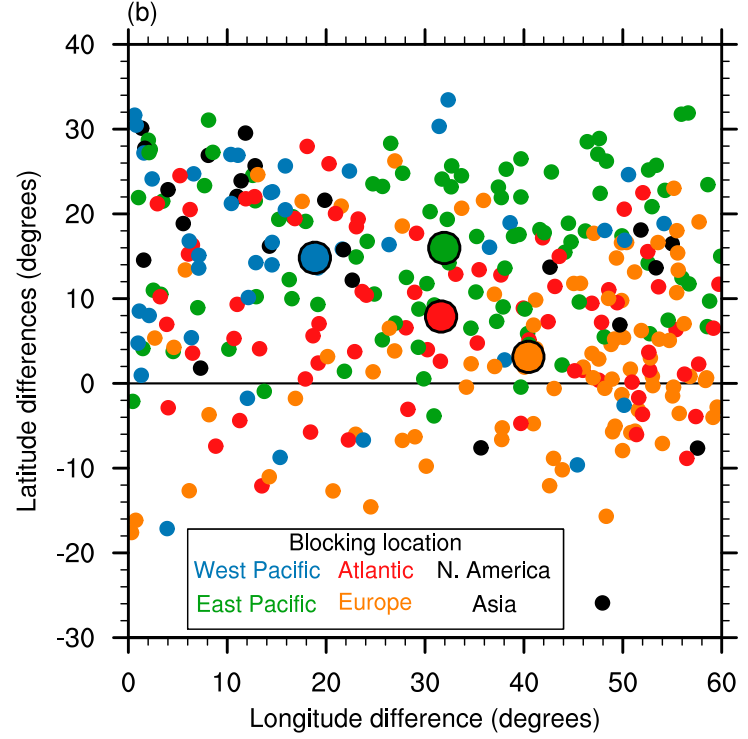

FIG. 5. The location of blocks that occurred within $60^{\circ}$ downstream and 5 days of any time on the track of a bomb. (a) Shading as in Fig. 3a, but for the subset of bomb tracks that are associated with a downstream block. The black dots indicate the location of blocks that are downstream of one bomb track; the magenta dots indicate the location of blocks that are downstream of multiple bomb tracks. (b) The difference between the blocking location and the associated average location of the bomb track colored by the region of the block, large circles indicate the average for that region.

rapid development of a surface cyclone. Of the 288 blocks identified in this study, 16 blocks occurred downstream of a point on the track of ET events; these blocks will hereafter be referred to as ET blocks. These 16 ET blocks were associated with 19 ET events (Fig. 6a). Although the most ET events occurred in the western Pacific, only 6 (31.6\%) of the 19 ET events that were associated with a downstream block occurred in the western Pacific (Fig. 6a). One event in the western Pacific, Typhoon Prapiroon in 2012, was associated with two downstream blocks (Fig. 6a). A total of 10 ET blocks were located in the Euro-Atlantic sector and were associated with 13 ET events. This means that ridges that form downstream of west Pacific ET events are more likely to be short-lived features while ridges that form downstream of Atlantic ET events are more likely to persist for days - these persistent ridges can have serious implications for European weather.

The average block strength of the ET blocks in the western Pacific and Europe are statistically significantly weaker at the $5 \%$ level than expected from a bootstrap resampling of all western Pacific and European blocks, respectively (Table 4). This suggests that blocks that form downstream of ET events tend to be weaker than blocks that form independent of ET events. The average extratropical interaction metric of the ET events associated with ET blocks are statistically indistinguishable from all ET events in their respective region, meaning that the magnitude of the extratropical interaction metric associated with ET events is not a necessarily indicative of whether a block will develop downstream.

In both the Pacific and the Euro-Atlantic sectors, blocks occurred on average about $30^{\circ}$ to the north of the average of all points on their upstream ET track (Fig. 6b). In the Euro-Atlantic sector the blocks occurred on average $38^{\circ}$ longitude downstream of the average ET track, whereas in the Pacific sector, blocks occurred on average $27^{\circ}$ longitude downstream of the average ET track. For both extratropical and tropical cyclones, downstream blocks in the west Pacific sector occurred zonally closer to the average cyclone track than downstream blocks in the Euro-Atlantic sector (Figs. 5b, 6b).

\section{e. ET events that produce long-lived extratropical cyclones}

Hart and Evans (2001) suggested that approximately half of all Atlantic ET events experience posttransition cyclone intensification, which includes an expansion of the high-impact wind field and large oceanic waves (e.g., Evans et al. 2017). In this study, a TC was deemed to have produced a long-lived extratropical cyclone if 1) any extratropical cyclone (i.e., cyclones that both qualified as bombs and those that did not) that lasted $\geq 2$ days and traversed $\geq 1000 \mathrm{~km}$ was identified within $5^{\circ}$ of the time and location of ET or the last time and location of the TC track, and 2) the extratropical cyclone track extended the TC track. The tropical-toextratropical tracks were created by appending the extratropical cyclone track from the MERRA-2 data to 
(a)
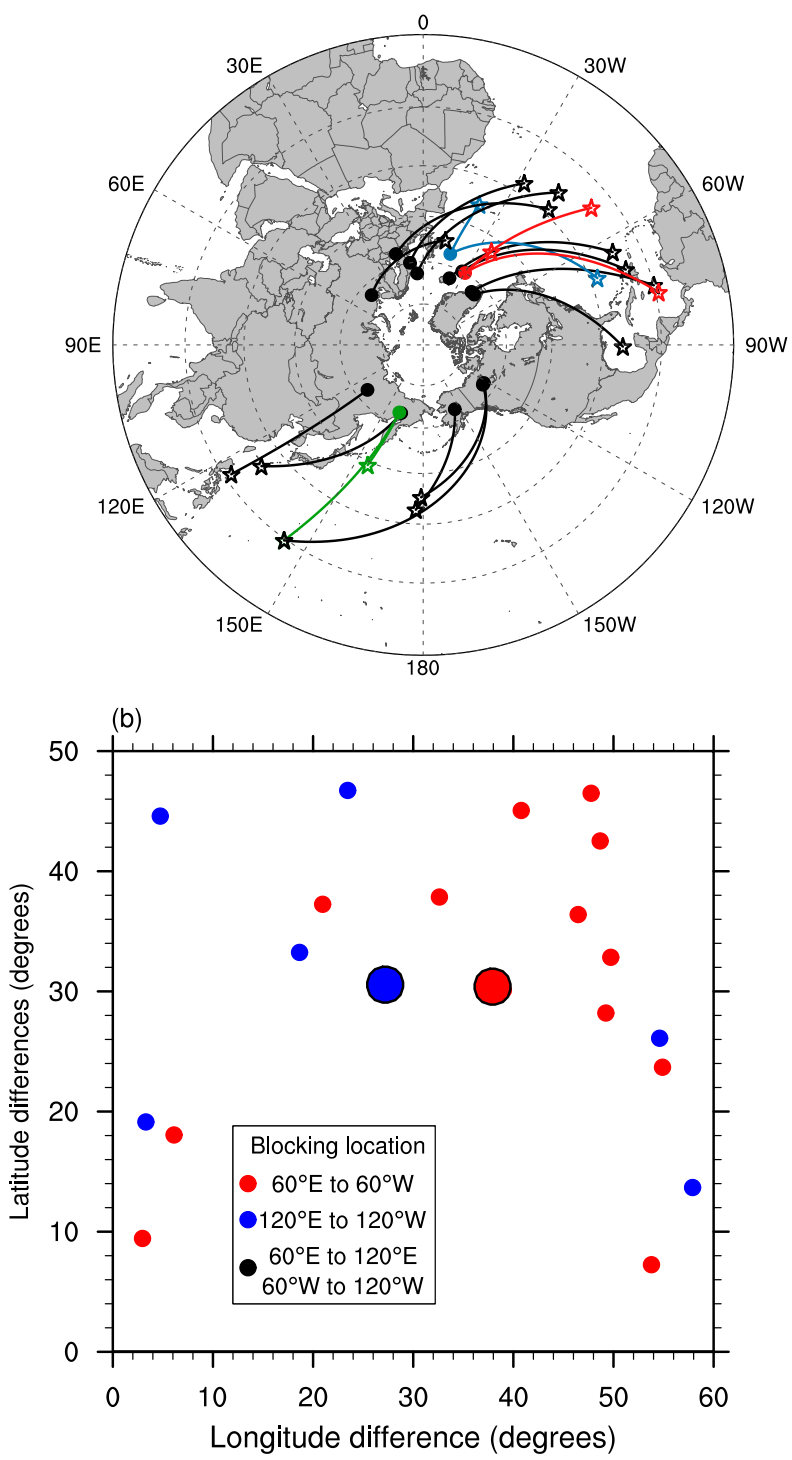

FIG. 6. (a) The location of the first time on the ET track that was associated with a downstream block (stars) and the location of the downstream block (dot). The colored pairs indicate blocks that are associated with multiple upstream ET events. (b) As in Fig. 5b, but for the average track location of ET events and their associated downstream blocks.

the TC track from the IBTrACS data at either the time of ET or the last time of the TC track data. Of the $151 \mathrm{ET}$ events, $116(77 \%)$ successfully transitioned to long-lived extratropical cyclones under this definition. In the western Pacific, the track density of these tropical-toextratropical tracks suggests a recurvature pathway that is consistent with the TC tracks of all ET events in the western Pacific (Fig. 4a) that extends northward past the date line to $150^{\circ} \mathrm{W}$ (Fig. 7a). This extension of the track frequency suggests that most ET events in the western
Pacific that successfully transition to extratropical cyclones continue poleward off the coast of Asia and then traverse northeastward toward the date line. In the Atlantic basin, the track frequency is quite broad in zonal extent but this subset of Atlantic ET events has a frequency maximum along the east coast of North America that is slightly larger than two mid-Atlantic maxima (Fig. 7a). The Atlantic basin tropical-to-extratropical cyclone tracks extend across the Atlantic and into Europe for cases that recurve and, for some cases that continue northward, farther into North America (Figs. 4a and 7a). Eight ET events that successfully continued as extratropical cyclones and two events that did not [Hurricane Noel (2001) and Super Typhoon Lupit (2009)] also met the bomb criteria (Fig. 7b). The notable difference between the ET-bomb events in the western Pacific and Atlantic is that for the three cases in the Atlantic, the explosive cyclogenesis occurred before the TC was identified as extratropical, whereas in the western Pacific, 5 out of the 7 TCs were identified as extratropical before rapidly deepening as bombs (Fig. 7b).

\section{Tropical-extratropical interaction}

a. $M J O$

The relationship between MJO convection and Northern Hemisphere blocking frequency shows that block-onset days are characterized by a statistically significant frequency maximum of the $\mathrm{MJO}_{7 \text { tol }}$ in phase 6 (Fig. 8a). While there are secondary $\mathrm{MJO}_{7 \text { to } 1}$ frequency maxima in phases 3 and 5 on block-onset days, they are not statistically significant with respect to all cool-season days (Fig. 8a). $\mathrm{MJO}_{7 \mathrm{to} 1}$ frequency minima during block-onset days occurred in phases 4 and 7 , with statistical significance only for the phase 7 minimum. These results suggests that in the week following MJO convection in the western Pacific (i.e., phase 6), there tends to be more blocking events in the high-latitude Northern Hemisphere, but as the MJO convection moves farther eastward across the western Pacific (i.e., phase 7) the frequency of blocking in the week following drastically decreases. The relationship between Northern Hemisphere blocking and the phases of the $\mathrm{MJO}_{7 \mathrm{to} 1}$ (Fig. 8a) showed a more robust signal than the relationship between blocks and the phase of the $\mathrm{MJO}_{14 \text { to } 8}$ (not shown).

The MJO phases with statistically significant Northern Hemisphere blocking frequency maxima and minima (i.e., phases 6 and 7, respectively) do not have a statistical relationship with the frequency of blocks by region (Fig. 8), suggesting that this statistical relationship is not 

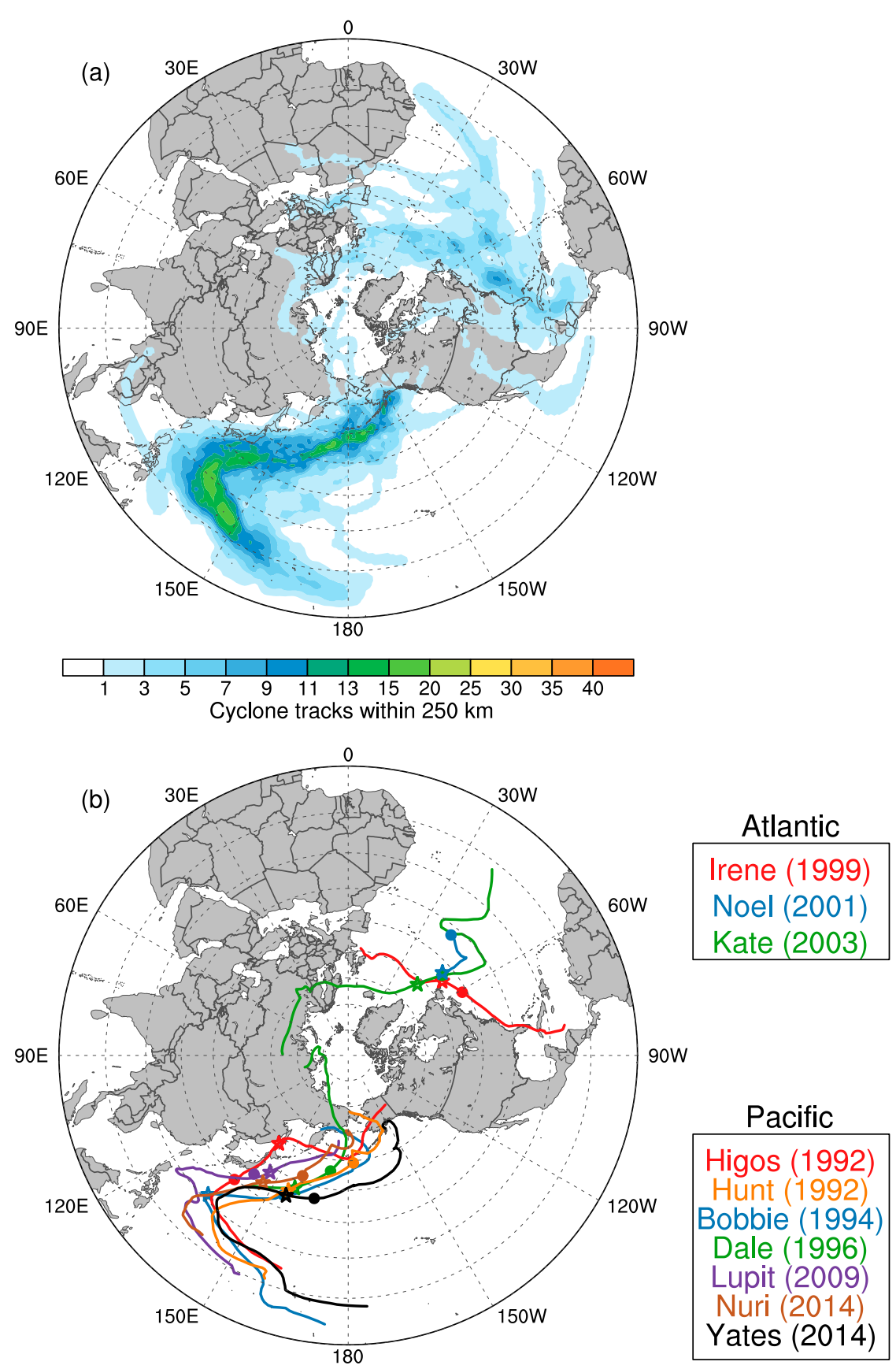

FIG. 7. (a) As in Fig. 4a, but for the tracks of ET events that were associated with long-lived extratropical cyclones $(n=116)$. (b) The tracks of the ET events that were also classified as bombs $(n=10)$, where the dot indicates the location of bomb and the star indicates the location of ET.

concentrated in a specific region. Nearly half of all blocks identified in the East Asia-west Pacific region, between $90^{\circ} \mathrm{E}$ and $180^{\circ}$, occurred with a weak $\mathrm{MJO}_{7 \mathrm{to} 1}$, which is statistically significant with respect to all identified blocks (Fig. 8b). There were also statistically significantly more blocks than expected between $0^{\circ}$ and $90^{\circ} \mathrm{E}$ and between $180^{\circ}$ and $90^{\circ} \mathrm{W}$ when the $\mathrm{MJO}_{7 \mathrm{to} 1}$ was in phases 2 and 5, respectively (Fig. 8b). When considering the statistical relationship between the $\mathrm{MJO}_{14 t o 8}$ and blocking location, the number of blocks that occurred between $180^{\circ}$ and $90^{\circ} \mathrm{W}$ was less than expected for eastern North Pacific blocks in phases 2 and 8 (not 


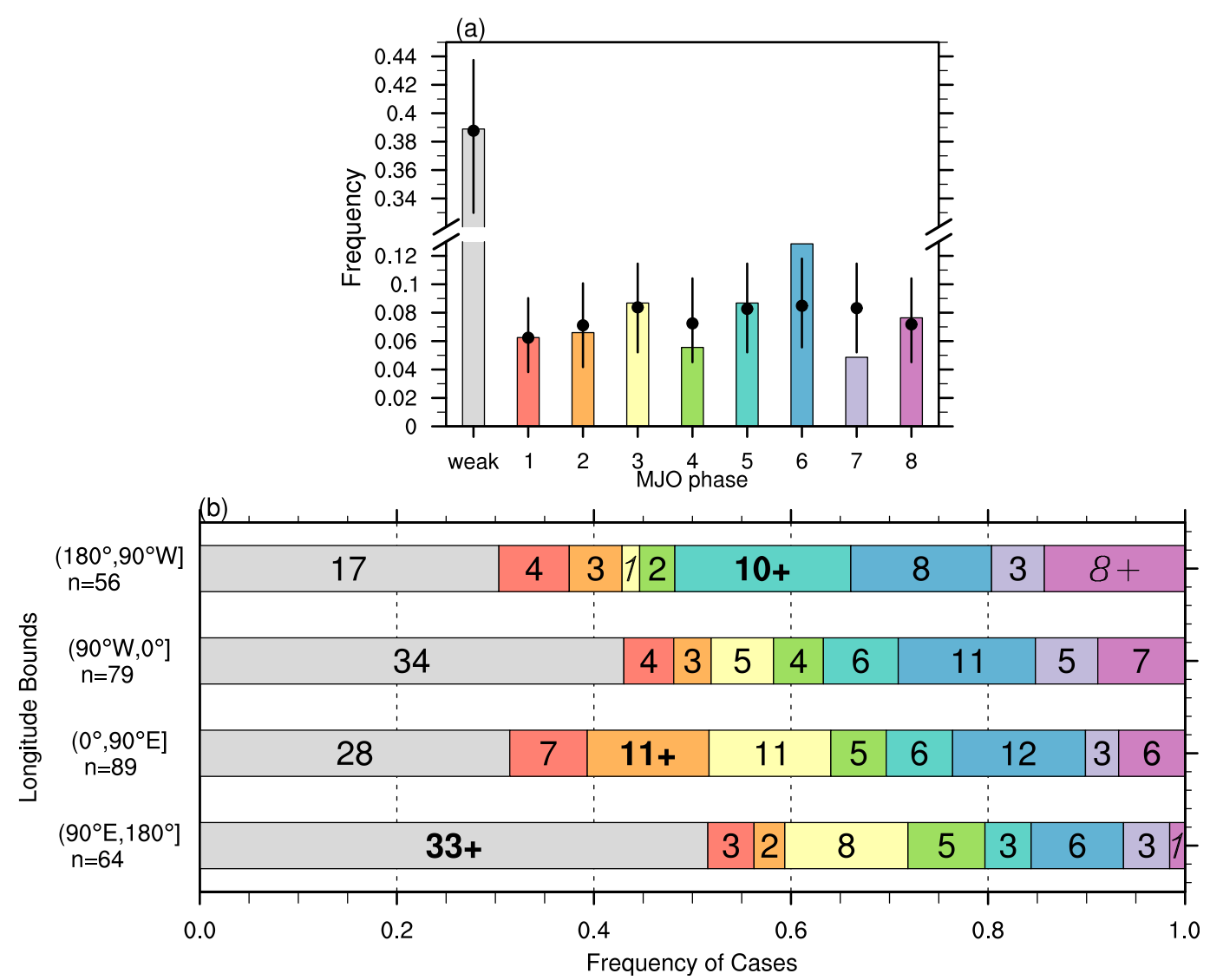

FIG. 8. The frequency $\left(\right.$ day $^{-1}$ ) of the phase of the $\mathrm{MJO}_{7 \text { to1 }}$ (see methods for definition) calculated for (a) all Northern Hemisphere blocks and (b) blocks partitioned by location. In (a) the dots indicate the corresponding $\mathrm{MJO}_{7 \mathrm{to} 1}$ frequency distribution for all cool-season days included in the study $(n=7428)$ and the vertical lines indicate the 95th percentile of the distribution. In (b) the number of blocks identified in each region and phase are shown as a stacked frequency diagram, with phases colored as in (a). Bold numbers denote statistical significance at the $5 \%$ level and italic numbers denote the statistical significance at the $10 \%$ level. The plus sign indicates that the number of blocks is above the 97.5 percentile or 95 percentile, and the minus sign indicates that the number of blocks is below the 2.5 percentile or 5 percentile. For the two categories that only have one block and are statistically significant at the $10 \%$ level, the minus sign is not included because of space constraints. In the longitude bounds the brackets and parentheses indicate inclusive and exclusive, respectively.

shown). This suggests that when MJO convection is in the Indian Ocean it impacts the Northern Hemisphere flow differently at different time scales. One week after MJO phase 2, the midlatitude flow is likely more amplified than normal (i.e., allowing for more eastern North Pacific blocks), but two weeks after MJO phase 2 the eastern Pacific-North America region is more zonal, decreasing the blocking potential. With respect to phase 8 convection, there is enhanced blocking associated with $\mathrm{MJO}_{7 \text { to1 }}$ (Fig. 8b) and suppressed blocking associated with $\mathrm{MJO}_{14 \text { to8 }}$ (not shown). This suggests that the immediate impact of Pacific MJO convection is to enhance blocking in the vicinity, but the lagged impact is to suppress blocking in the vicinity. The relationship between the phase of the MJO prior to the onset of blocks across the Northern Hemisphere is not consistent with the results of Henderson et al. (2016), which is attributed to the methodological differences in the blocking definitions (e.g., one dimensional vs two dimensional) and statistical testing. However, these results are consistent with Gollan and Greatbatch (2017) who also showed an increase in high-latitude blocking following MJO phase 6 convection, though their local maximum was located in the Euro-Atlantic sector.

Northern Hemisphere bomb days exhibit a statistically significant minimum during weak $\mathrm{MJO}_{7 \text { to1 }}$ convection and maxima during $\mathrm{MJO}_{7 \text { to } 1}$ phases 6 and 7 (Fig. 9a). This suggests that immediately following west Pacific MJO convection, the frequency of Northern Hemisphere explosive cyclogenesis increases, though this increase is not confined to a certain region or latitude band (Figs. 9b,c). In the Atlantic quadrant (i.e., 
(b)
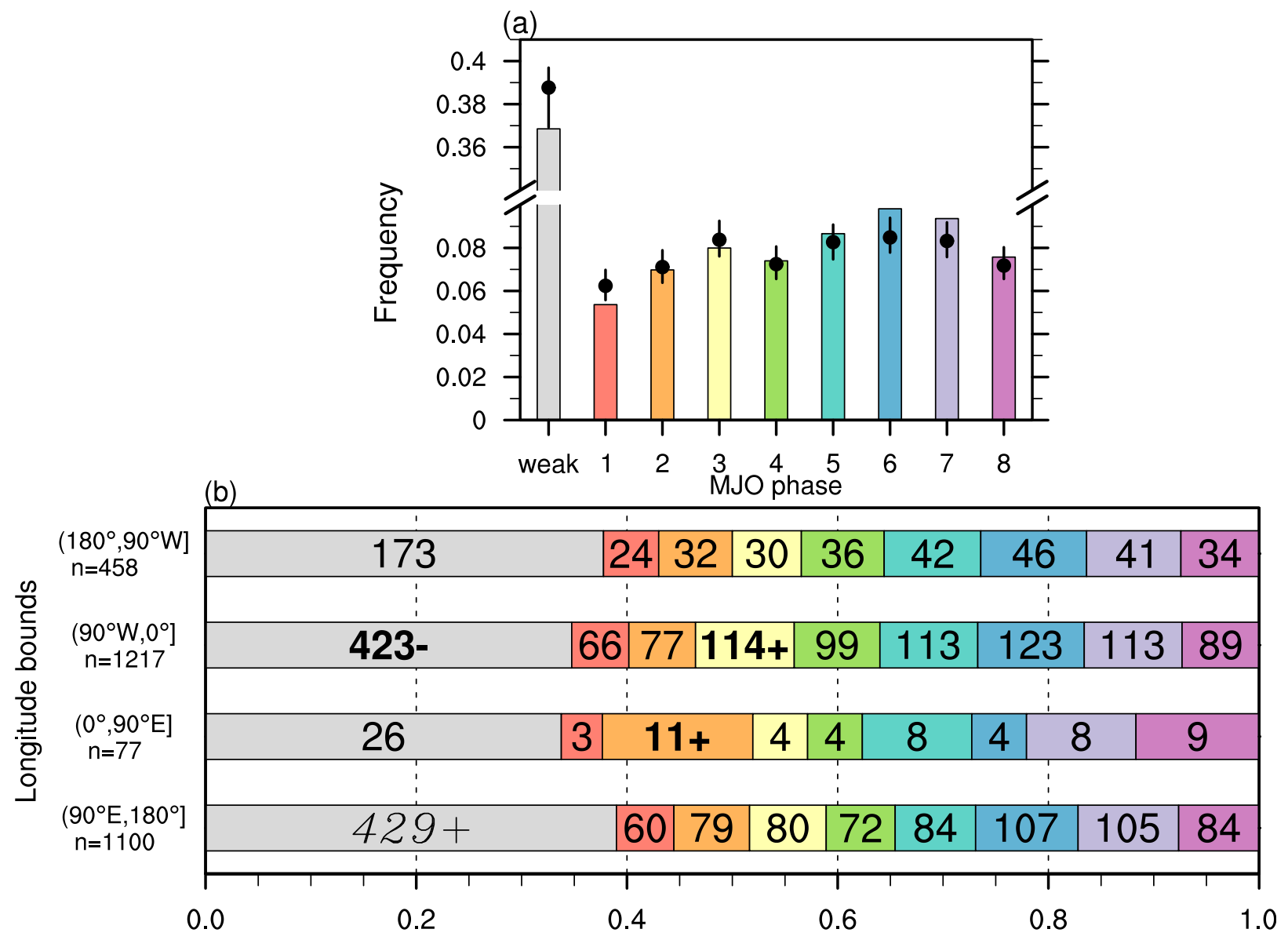

(c)

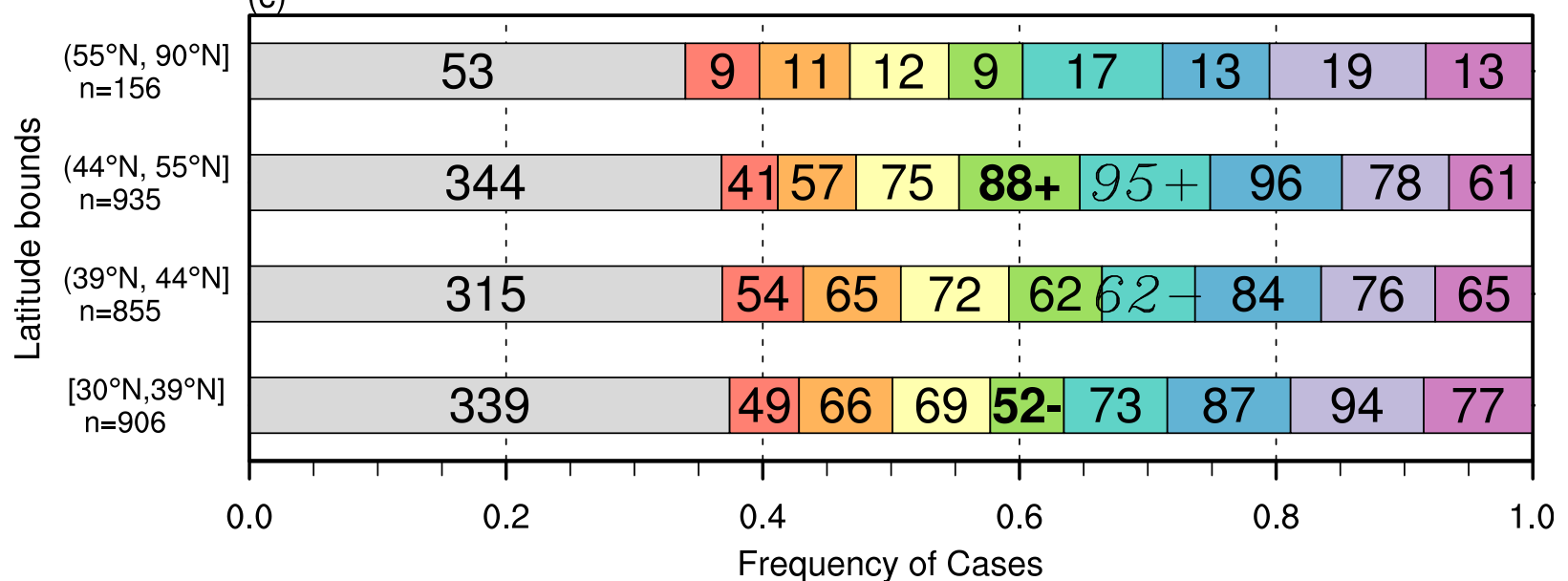

FIG. 9. As in Fig. 8, but for bombs $(n=2852)$, and in (c) the distribution of bombs by latitude bands.

between $90^{\circ} \mathrm{W}$ and $0^{\circ}$ ), however, there is a statistically significant decrease in bomb frequency associated with weak $\mathrm{MJO}_{7 \mathrm{to1}}$ convection and increase associated with $\mathrm{MJO}_{7 \text { to1 }}$ phase 3 convection (Fig. 9b). There is also a statistically significant increase in bomb frequency between $0^{\circ}$ and $90^{\circ} \mathrm{E}$ when $\mathrm{MJO}_{7 \mathrm{to} 1}$ is in phase 2 .
With respect to latitude band, bomb frequency is shifted poleward immediately following $\mathrm{MJO}$ convection in the Maritime Continent (i.e., $\mathrm{MJO}_{7 \mathrm{to} 1}$ phases 4 and 5), as seen from the statistically significant decrease in bomb frequency between $30^{\circ}$ and $44^{\circ} \mathrm{N}$ and increase between $44^{\circ}$ and $55^{\circ} \mathrm{N}$ (Fig. 9c). Considering the panels of Fig. 9 


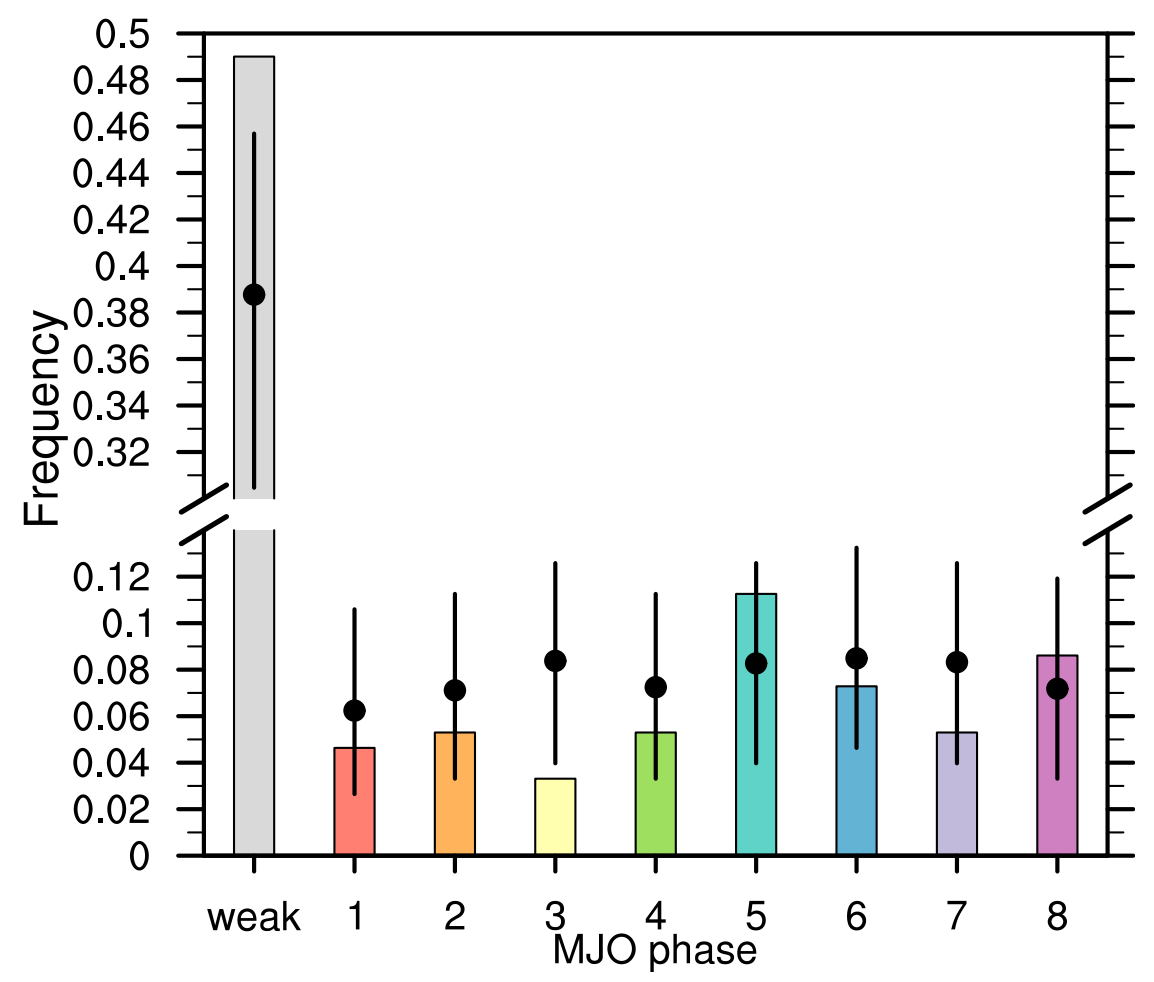

FIG. 10. As in Fig. 8a, but for ET events $(n=151)$.

together, suggests that the largest impact on regional midlatitude explosive cyclogenesis occurs when $\mathrm{MJO}_{7 \text { tol }}$ convection is confined between the Indian Ocean and Maritime Continent (i.e., phases 2-5), but that the largest impact on the frequency of Northern Hemisphere explosive cyclogenesis occurs when the $\mathrm{MJO}_{7 \text { to1 }}$ convection is in the west Pacific (i.e., phases 6 and 7).

Comparing ET days to all cool-season days reveals a statistically significant minimum in $\mathrm{MJO}_{7 \text { to } 1}$ in phase 3 (Fig. 10), suggesting that immediately following the MJO in phase 3, the likelihood of Northern Hemisphere ET occurrence is smaller than expected. While there are no statistically significant relationships between $\mathrm{MJO}_{7 \text { to1 }}$ and ET occurrence by basin, there are less west Pacific ET events than expected following $\mathrm{MJO}_{14 \text { to } 8}$ in phase 4. There is also a statistically significant maximum for all Northern Hemisphere events following weak $\mathrm{MJO}_{7 \text { to1 }}$ suggesting that periods lacking MJO convection are likely to precede ET events (Fig. 10).

\section{b. ENSO}

ENSO shows only statistically significant relationships with Northern Hemisphere bomb and ET frequency, and only for particular phases of ENSO (Fig. 11). Block, bomb, and ET onset all have maxima during neutral ENSO conditions, which is expected based on the climatology for all cool-season days. However, the frequency of neutral ENSO conditions on bomb days is statistically significantly less than expected with respect to all cool-season days, suggesting that cyclones that meet the bomb criteria occur less frequently under neutral ENSO conditions. Bomb-onset days have a statistically significant higher frequency of strong La Niña and El Niño conditions than expected from all cool-season days (Fig. 11), suggesting bombs are more frequent under strong La Niña and El Niño conditions.

ET days only have a statistically significant relationship with weak La Niña regimes, such that the ET frequency is statistically significantly smaller than expected at the $10 \%$ level with respect to all cool-season days (Fig. 11). While east Pacific ET events only make up a small percentage of the ET events studied, this result is consistent with Wood and Ritchie (2014) who showed that no east Pacific TCs underwent ET during La Niña years. ET latitude is statistically significantly shifted equatorward under strong El Niño conditions (Table 5).

Although the Northern Hemisphere blocking frequency (Fig. 11) and regional blocking frequency (not shown) showed no statistical relationship with ENSO, block duration showed a statistical relationship with neutral ENSO conditions. Under neutral ENSO conditions, blocks are statistically significantly longer than a random sampling of all identified blocks (Table 5). Barriopedro et al. (2006) also showed no statistical 


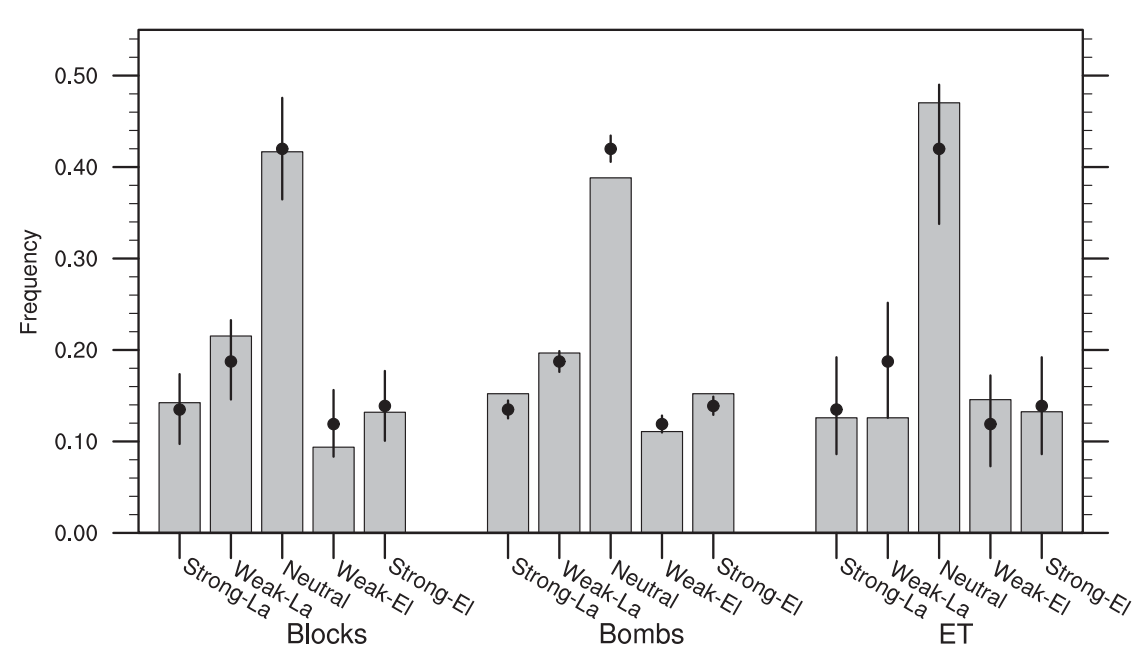

FIG. 11. As in Fig. 8a, but for the ENSO phase frequency $\left(\right.$ days $^{-1}$ ) at the onset of blocks, bombs, and ET events.

relationship between the frequency of blocking and ENSO. However, Barriopedro et al. (2006) showed that blocks are longer during La Niña conditions.

Bomb-onset latitude is also statistically significant based on ENSO conditions, with bombs occurring at an anomalously southern latitude $\left(42.2^{\circ} \mathrm{N}\right)$ during weak El Niño conditions (Table 5). This anomalously equatorward bomb-onset location for weak El Niño regimes is consistent with Eichler and Higgins (2006), who showed an equatorward shift in the storm track during El Niño conditions.

The frequency distribution of the phase of ENSO on bomb-block days is only statistically different than expected from all cool-season days during weak El Niño conditions, such that there are fewer bomb blocks than expected (Table 5). The blocking duration of bomb blocks is statistically longer (6.7 days) than expected under neutral ENSO conditions, consistent with all blocks.

\section{c. $Q B O$ and $Q B O$ shear}

Similar to the analysis of the ENSO-synoptic event relationship, only Northern Hemisphere bomb and ET frequency have a statistically significant relationship with certain phases of the QBO and QBO shear. The distribution of blocking with respect to QBO and
QBO-shear phases is similar to the expected distributions for all cool-season days (Fig. 12a). For ET events there is a statistically significant minimum in the frequency of neutral QBO conditions (Fig. 12a). This result suggests that ET events are less likely to occur during neutral QBO conditions. Considering QBO shear, ET days have a frequency maximum for easterly QBOshear conditions (i.e., cold thermal anomaly) and a minimum for westerly QBO-shear conditions (i.e., warm thermal anomaly; Fig. 12a). These QBO shear-ET relationships are statistically significant at the $10 \%$ level (not shown) with respect to all cool-season days, suggesting that the sign in the wind shear of the equatorial lower stratosphere, which is linked via the thermal-wind relationship to thermal anomalies in the lower stratosphere, likely impact the low-frequency variability of ET occurrence. The mechanism to describe this relationship is currently under investigation.

With respect to bombs, the frequency of neutral QBO and neutral QBO-shear conditions are statistically significant larger than expected for bomb days compared to all cool-season days (Fig. 12a). Furthermore, the easterly QBO shear and westerly QBO frequency on bomb days is statistically significantly smaller than expected from a sampling of all cool-season days (Fig. 12a). These results suggest that bombs occur more frequently in the

TABLE 5. The relationship between ENSO and characteristics of the synoptic events.

\begin{tabular}{lccccc}
\hline \hline ENSO phase & Block length (days) & Bomb lat $\left({ }^{\circ} \mathrm{N}\right)$ & ET lat $\left({ }^{\circ} \mathrm{N}\right)$ & Bomb-block count $(\mathrm{n})$ & Bomb-block length $($ days $)$ \\
\hline Strong La Niña & 5.9 & 43.6 & 36.2 & 28 & 5.9 \\
Weak La Niña & 6.2 & $\mathbf{4 2 . 2 -}$ & 35.0 & 41 & 6.0 \\
Neutral & $\mathbf{6 . 6 +}$ & 43.3 & 36.2 & 75 & $\mathbf{6 . 7 +}$ \\
Weak El Niño & 5.7 & 42.9 & 35.7 & $\mathbf{1 2}-$ & 5.8 \\
Strong El Niño & 5.5 & 42.9 & $\mathbf{3 1 . 6}$ & 27 & 5.6 \\
\hline
\end{tabular}




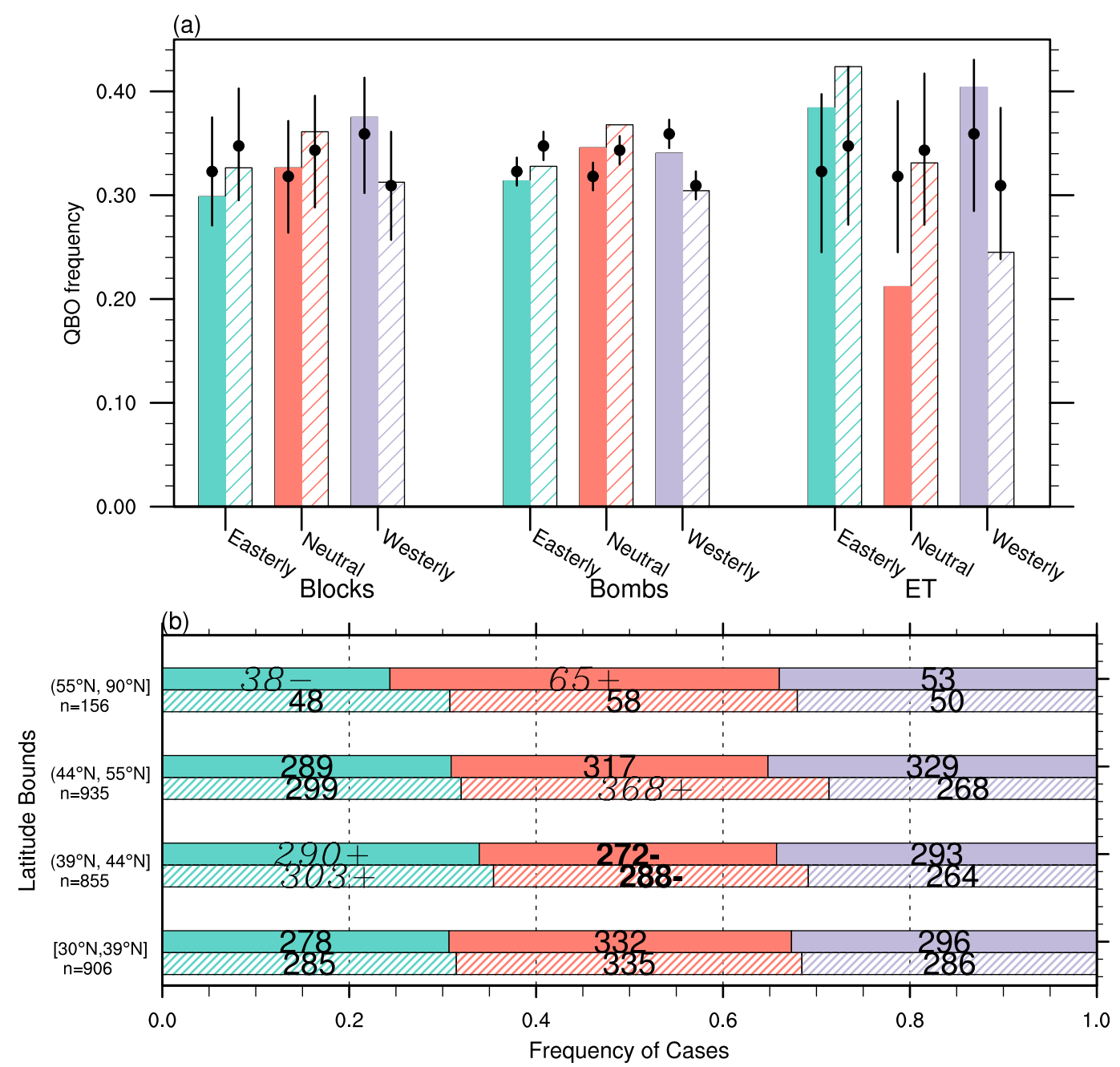

FIG. 12. As in Fig. 8 but for (a) the QBO (solid fill) and QBO-shear (line fill) phase frequency (day ${ }^{-1}$ ) and (b) the number bombs partitioned by latitude bands and QBO and QBO-shear phase.

Northern Hemisphere during neutral QBO and neutral QBO-shear conditions and less frequently in easterly QBO-shear and westerly QBO conditions. The neutral QBO and QBO-shear conditions also show a statistical relationship with the location of bombs at the $5 \%$ level, such that bombs in the $39^{\circ}$ and $42^{\circ} \mathrm{N}$ latitude band occur less often than expected (Fig. 12b). Considering also the $10 \%$ statistical significant level, bomb-onset latitude is shifted poleward under neutral QBO-shear conditions with a significant increase in the frequency of bombs between $44^{\circ}$ and $55^{\circ} \mathrm{N}$. For neutral QBO, there is a significant increase in bomb-onset frequency poleward of $55^{\circ} \mathrm{N}$. At the $10 \%$ level, there is also a robust statistical relationship between easterly QBO and QBO-shear conditions and bomb frequency (Fig. 12b). Under easterly QBO conditions, Arctic bomb frequency (i.e., poleward of $55^{\circ} \mathrm{N}$ ) is significantly less than expected and accompanied by a significant increase in bomb frequency between $39^{\circ}$ and $44^{\circ} \mathrm{N}$. There is also a significant increase in bomb frequency between $39^{\circ}$ and $44^{\circ} \mathrm{N}$ during easterly QBO-shear conditions. The relationship between the frequency and location of bombs and the QBO suggests that low-frequency variability in the equatorial stratosphere may exert an influence on Arctic weather, such that bomb onset is shifted equatorward under easterly conditions, but poleward under neutral conditions. This tropical stratosphereextratropical troposphere relationship should be investigated further to fully account for the mechanisms in which the QBO influences tropospheric climate.

\section{Summary and discussion}

Case lists of blocks, bombs, and the ET of TCs were compiled for analysis with NASA's MERRA-2 and the 
IBTrACS datasets for the Northern Hemisphere cool seasons (October-April) of 1980-2015. The first part of the analysis consisted of a climatological analysis that 1) examined the climatological distribution, frequency, and strength of blocks, bombs, and the ET events; and 2) identified the distribution of bomb-blocks, ET-blocks, and ET events that produce long-lived extratropical cyclones, including ET bombs.

In addressing research question 1 , the location and frequency of blocks $(n=288)$ and bombs $(n=2852)$ identified in the MERRA-2 dataset are shown to be consistent with the climatological distribution of these events from the seminal analyses of Tibaldi and Molteni (1990) and Sanders and Gyakum (1980), respectively (Figs. 2a and 3a). Blocking frequency maxima occurred in the Euro-Atlantic and Pacific regions while bomb frequency maxima occurred in the western Pacific and western Atlantic. The maximum extratropical interaction of ET events $(n=151)$, represented by the PV advection by the irrotational wind, was calculated within $\pm 96 \mathrm{~h}$ of the time of ET for TCs that occurred in the western Pacific, eastern Pacific, and Atlantic basins. The corresponding average extratropical interactions values for the ET events in the west Pacific, east Pacific, and Atlantic basins are $-0.95,-0.37$, and $-0.58 \mathrm{PVU}$ day $^{-1}$, respectively (Fig. 4b). This shows that cool-season west Pacific ET events have the largest mean impact on the upper-tropospheric midlatitude flow out of all coolseason ET events that occur in the three main Northern Hemisphere TC basins.

Out of the 288 identified cool-season blocks, 183 blocks occurred within $60^{\circ}$ downstream and 5 days of a time on a bomb cyclone track (Fig. 5a). Over $68 \%$ of the blocks identified in each region from the east Pacific eastward through Europe fits this bomb-block definition. A subset of 16 blocks occurred within $60^{\circ}$ downstream and 5 days of a time on an ET track with the majority of the ET events occurring in the Atlantic sector (Fig. 6a). Of the $151 \mathrm{ET}$ events, $116 \mathrm{ET}$ events successfully continued as extratropical cyclones that lasted $\geq 2$ days (Fig. 7a), and 10 ET events were also identified as bombs (Fig. 7b).

In addressing research question 2 , the analysis considered the frequency of these synoptic events with respect to low-frequency variability in the tropics by examining the statistical differences in the frequency of the phases of the MJO, ENSO, QBO, and QBO shear on all cool-season days, block-onset, bomb-onset, and ET days. Both QBO and QBO shear were used to capture the low-frequency variability in the equatorial stratospheric momentum and thermal fields, respectively.

Of these three tropical modes analyzed, Northern Hemisphere blocking only showed a statistical relationship with certain phases of the MJO during lag days -7 to -1
$\left(\mathrm{MJO}_{7 \mathrm{to1}}\right)$. There is a statistically significant blocking frequency maximum for $\mathrm{MJO}_{7 \text { to1 }}$ phase 6 and a frequency minimum for $\mathrm{MJO}_{7 \text { to1 }}$ phase 7 (Fig. 8a). Northern Hemisphere bomb frequency, however, showed a statistical relationship with all analyzed tropical modes: $\mathrm{MJO}_{7 \mathrm{to} 1}$, ENSO, QBO, and QBO shear. With respect to ENSO, there is bomb frequency minimum during neutral ENSO conditions and maxima during strong La Niña and strong El Niño conditions (Fig. 11a). With respect to the QBO, there is a bombing frequency maximum during neutral QBO and QBOshear conditions and minima during easterly QBO and westerly QBO-shear conditions (Fig. 12a). Considering the location of bombs, bomb onset that occurred from $90^{\circ} \mathrm{W}$ through the prime meridian to $90^{\circ} \mathrm{E}$ had a statistical relationship with $\mathrm{MJO}_{7 \mathrm{to} 1}$, such that there is less bomb onset following weak MJO conditions and more bomb onset following MJO convection in phases 2 and 3 (Fig. 9b). The latitude of bomb onset is displaced poleward when $\mathrm{MJO}_{7 \mathrm{to1}}$ is in phase 4 (Fig. 9c). Bomb frequency poleward of $39^{\circ} \mathrm{N}$, including Arctic bombs (i.e., bombs that occur poleward of $55^{\circ} \mathrm{N}$ ) have a statistically significant relationship with easterly and neutral QBO and QBO-shear conditions (Fig. 12b). Shifts in the latitude bins of bomb onset suggest that bombs are displaced equatorward during easterly QBO and QBO-shear conditions and poleward during neutral QBO and QBO-shear conditions. Coolseason ET events also show a statistical relationship with phases of all three analyzed modes of tropical variability (Figs. 10, 11, and 12a). This ET-tropical variability relationship includes the following: 1) a maximum following weak MJO conditions, 2) a minimum following MJO phase 3,3 ) a minimum during weak La Niña conditions, and 4) a minimum during neutral QBO conditions.

The MJO-block relationship identified in this study that showed enhanced blocking in the eastern Pacific/ western North America (i.e., $180^{\circ}-90^{\circ} \mathrm{W}$ ) following phase 5 of the $\mathrm{MJO}_{7 \text { to1 }}$ is consistent with the conceptual description of the MJO. When there is anomalous convection over the Maritime Continent, as is described by phase 5 of the MJO, the upper-tropospheric outflow associated with the convection can advect lower PV air poleward to influence the extratropical waveguide at a similar longitude, thus impacting preferred regions for ridging and blocked longitudes [e.g., Fig. $8 \mathrm{~b}$ in Rui and Wang (1990)]. Since the MJO tends to be strongest in the Western Hemisphere, it is not surprising that phase 5 of MJO convection influences extratropical blocking.

The physical mechanisms that could account for the MJO-bomb relationship are more indirect than the MJO-block relationship. The MJO-bomb relationship shows a strong statistical link with Northern Hemisphere bomb frequency, bomb longitude, and bomb latitude for 


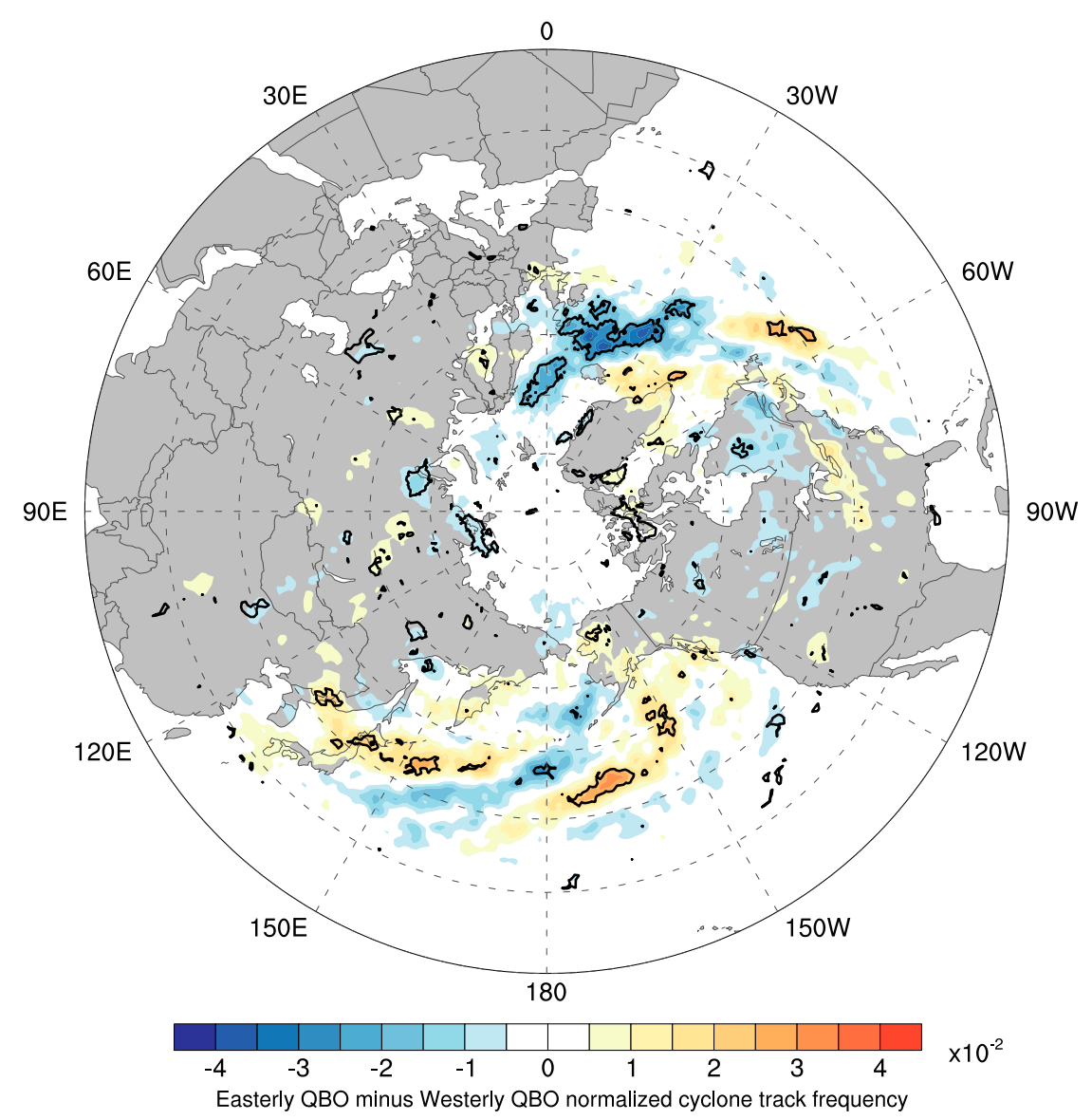

FIG. 13. The normalized difference between cyclone track density for cyclones that undergo explosive cyclogenesis during the easterly phase of the QBO and the westerly phase of the QBO. The frequencies in each location are normalized by the total number of bombs in that phase of the QBO. Black contours indicate where the difference is statistically significant at the $5 \%$ level.

different phases of the MJO. The MJO bomb-latitude relationship suggests that the MJO impacts the preferred latitude of storm-track exit regions, which is one of the climatological regions where bombs develop.

When considering both the MJO-bomb and QBObomb relationships, an interesting signal emerges. The MJO-bomb relationship shows a signal equatorward of $55^{\circ} \mathrm{N}$ while the $\mathrm{QBO}-$ bomb relationship shows a relationship poleward of $55^{\circ} \mathrm{N}$. This suggests that mechanisms by which these oscillations impact the extratropics are different. The result is consistent with Wang et al. (2018) who suggested that partitioning MJO impacts on the North Pacific storm track by phase of the QBO needs to be considered to better describe the tropicalextratropical teleconnections. Wang et al. (2018) showed that during easterly QBO and MJO phases 2 and 3 the North Pacific storm track is more zonally elongated than during the westerly QBO phase. Figure 13 shows a similar signal to Wang et al. (2018) in that there is a statistically significantly larger frequency of bomb tracks in the west Pacific and near $165^{\circ} \mathrm{W}$ during easterly QBO periods than westerly QBO periods. Wang et al. (2018) suggest that the observed differences in the spatial distribution of the storm track is a direct result of the QBO and their Fig. 11 provides a conceptual diagram that suggests the pathway through which the QBO impacts the North Pacific storm track. They suggest that during easterly QBO years there is anomalously enhanced baroclinicity in the high latitudes increasing storminess in the Pacific (Wang et al. 2018). This QBO-extratropical bomb relationship is also consistent with Garfinkel and Hartmann (2011) who showed that during easterly QBO years the subtropical Pacific jet is weaker, increasing the waviness of the extratropical flow and creating a favorable environment for cyclone development. Not only does the QBO impact the North Pacific storm track, but Fig. 13 also shows statistical differences in the frequency of bomb tracks in the Atlantic, consistent with Asbaghi et al. (2017). Figure 13 shows statistically 
significantly fewer bombs in the northeastern Atlantic during the easterly phase of the QBO, which is consistent with Fig. 1f of Asbaghi et al. (2017), which shows statistically significantly more eddy kinetic energy in the same region during westerly QBO conditions in the late winter (i.e., January-March).

In addressing research question 3, this work suggests statistical associations between tropical modes of variability and extratropical weather systems. When considering extreme synoptic events, the results suggest that low-frequency variability in the equatorial stratosphere, described by the QBO and QBO shear, can have relationships on the same order of magnitude as those associated with low-frequency variability in the equatorial troposphere (e.g., MJO and ENSO). Furthermore, the tropical variability in the troposphere and stratosphere are associated with spatially different impacts that may inform subseasonal outlooks of extreme synoptic events. Future work is needed to examine the dynamical and physical mechanisms associated with the tropical stratosphere and extratropical weather relationships identified in this analysis.

Acknowledgments. The authors thank Kevin Hodges for supplying the extratropical cyclone tracking code and Kevin Tyle for his help compiling the code. This work was supported by NASA Headquarters under the NASA Earth and Space Science Fellowship Program Grant NNX16AO01H awarded to the first author. Additionally, this research was conducted as part of the NOAA MAPP S2S Prediction Task Force and supported by NOAA Grant NA16OAR4310068 and the National Science Foundation Award 1547814. We would also like to thank the three anonymous reviewers and the editor for their helpful comments that greatly improved the quality of this manuscript. The MERRA-2 dataset is listed in the references and can be found at https://gmao.gsfc.nasa.gov/ reanalysis/MERRA-2/data_access/. Data for the QBO, ENSO, and MJO are from http://www.cpc.ncep.noaa.gov/ data/indices/, https://origin.cpc.ncep.noaa.gov/products/ analysis_monitoring/ensostuff/ONI_v5.php, and http://www. bom.gov.au/climate/mjo/graphics/rmm.74toRealtime.txt, respectively.

\section{REFERENCES}

Archambault, H. M., L. F. Bosart, D. Keyser, and J. M. Cordeira, 2013: A climatological analysis of the extratropical flow response to recurving western North Pacific cyclones. Mon. Wea. Rev., 141, 2325-2346, https://doi.org/10.1175/MWR-D-12-00257.1.

Asbaghi, G., M. Joghataei, and A. R. Mohebalhojeh, 2017: Impacts of the QBO on the North Atlantic and Mediterranean storm tracks: An energetic perspective. Geophys. Res. Lett., 44, 1060-1067, https://doi.org/10.1002/2016GL072056.
Baldwin, M. P., and Coauthors, 2001: The quasi-biennial oscillation. Rev. Geophys., 39, 179-229, https://doi.org/10.1029/ 1999RG000073.

Barnes, E. A., E. Dunn-Sigouin, G. Masato, and T. Woollings, 2014: Exploring recent trends in Northern Hemisphere blocking. Geophys. Res. Lett., 41, 638-644, https://doi.org/ 10.1002/2013GL058745.

Barriopedro, D., R. García-Herrera, A. R. Lupo, and E. Hernández, 2006: A climatology of Northern Hemisphere blocking. J. Climate, 19, 1042-1063, https://doi.org/10.1175/ JCLI3678.1.

- - , and R. M. Trigo, 2010: Application of blocking diagnosis methods to general circulation models. Part I: A novel detection scheme. Climate Dyn., 35, 1373-1391, https:// doi.org/10.1007/s00382-010-0767-5.

Berrisford, P., B. J. Hoskins, and E. Tyrlis, 2007: Blocking and Rossby wave breaking on the dynamical tropopause in the Southern Hemisphere. J. Atmos. Sci., 64, 2881-2898, https:// doi.org/10.1175/JAS3984.1.

Bosart, L. F., and S. C. Lin, 1984: A diagnostic analysis of the Presidents' Day storm of February 1979. Mon. Wea. Rev., 112, 2148-2177, https://doi.org/10.1175/1520-0493(1984)112<2148: ADAOTP $>2.0 . \mathrm{CO} ; 2$.

Bosilovich, M. G., and Coauthors, 2015: MERRA-2: Initial evaluation of the climate. Tech. Rep. NASA/TM-2015-104606/ Vol. 43, NASA, 145 pp., https://gmao.gsfc.nasa.gov/pubs/docs/ Bosilovich803.pdf.

Chen, S.-J., Y.-H. Kuo, P.-Z. Zhang, and Q.-F. Bai, 1992: Climatology of explosive cyclones off the East Asian coast. Mon. Wea. Rev., 120, 3029-3035, https://doi.org/10.1175/1520-0493 (1992) $120<3029$ :COECOT $>2.0$. CO 2 .

Climate Prediction Center, 2006: Blocking index. NOAA/NWS, accessed 15 February 2016, http://www.cpc.ncep.noaa.gov/ products/precip/CWlink/blocking/index/index.nh.shtml.

Colucci, S. J., and T. L. Alberta, 1996: Planetary-scale climatology of explosive cyclogenesis and blocking. Mon. Wea. Rev., 124, 2509-2520, https://doi.org/10.1175/1520-0493(1996)124<2509: PSCOEC $>2.0 . \mathrm{CO} ; 2$.

— , and M. E. Kelleher, 2015: Diagnostic comparison of tropospheric blocking events with and without sudden stratospheric warming. J. Atmos. Sci., 72, 2227-2240, https://doi.org/10.1175/ JAS-D-14-0160.1.

Coy, L., and S. Pawson, 2015: The major stratospheric sudden warming of January 2013: Analyses and forecasts in the GOES-5 data assimilation system. Mon. Wea. Rev., 143, 491510, https://doi.org/10.1175/MWR-D-14-00023.1.

Eichler, T., and W. Higgins, 2006: Climatology and ENSO-related variability of North American extratropical cyclone activity. J. Climate, 19, 2076-2093, https://doi.org/10.1175/JCLI3725.1.

Evans, C., and Coauthors, 2017: The extratropical transition of tropical cyclones. Part I: Cyclone evolution and direct impacts. Mon. Wea. Rev., 145, 4317-4344, https://doi.org/10.1175/ MWR-D-17-0027.1.

Garfinkel, C. I., and D. L. Hartmann, 2011: The influence of the quasi-biennial oscillation on the troposphere in winter in a hierarchy of models. Part I: Simplified dry GCMs. J. Atmos. Sci., 68, 1273-1289, https://doi.org/10.1175/2011JAS3665.1.

- S. B. Feldstein, D. W. Waugh, C. Yoo, and S. Lee, 2012: Observed connection between stratospheric sudden warmings and the Madden-Julian Oscillation. Geophys. Res. Lett., 39, L18807, https://doi.org/10.1029/2012GL053144.

Gelaro, R., and Coauthors, 2017: The Modern-Era Retrospective Analysis for Research and Applications, version 2 (MERRA-2). 
J. Climate, 30, 5419-5454, https://doi.org/10.1175/JCLI-D-160758.1.

GMAO, 2015: MERRA-2 inst3_3d_asm_np:3d,3-hourly,instantaneous, pressure-level,assimilation, assimilated meteorological fields v5.12.4. Goddard Earth Sciences Data and Information Services Center (GES DISC), Greenbelt, MD, accessed 1 August 2016, https://doi.org/10.5067/QBZ6MG944HW0.

Gollan, G., and R. J. Greatbatch, 2017: The relationship between Northern Hemisphere winter blocking and tropical modes of variability. J. Climate, 30, 9321-9337, https://doi.org/10.1175/ JCLI-D-16-0742.1.

Grams, C. M., and S. R. Blumer, 2015: European high-impact weather caused by the downstream response to the extratropical transition of North Atlantic Hurricane Katia (2011). Geophys. Res. Lett., 42, 8738-8748, https://doi.org/10.1002/2015GL066253.

Gray, L. J., J. A. Anstey, Y. Kawatani, H. Lu, S. Osprey, and V. Schenzinger, 2018: Surface impacts of the quasi biennial oscillation. Atmos. Chem. Phys., 18, 8227-8247, https://doi.org/ 10.5194/acp-18-8227-2018.

Hart, R. E., and J. L. Evans, 2001: A climatology of the extratropical transition of Atlantic tropical cyclones. J. Climate, 14, 546-564, https://doi.org/10.1175/1520-0442(2001)014<0546: ACOTET $>2.0 . \mathrm{CO} ; 2$

Henderson, S. A., E. D. Maloney, and E. A. Barnes, 2016: The influence of the Madden-Julian oscillation on Northern Hemisphere winter blocking. J. Climate, 29, 4597-4616, https://doi.org/10.1175/JCLI-D-15-0502.1.

Higgins, R. W., and K. C. Mo, 1997: Persistent North Pacific circulation anomalies and the tropical intraseasonal oscillation. J. Climate, 10, 223-244, https://doi.org/10.1175/1520-0442 (1997)010<0223:PNPCAA $>2.0$. CO;2.

Hodges, K. I., 1994: A general method for tracking analysis and its application to meteorological data. Mon. Wea. Rev., 122, 2573-2586, https://doi.org/10.1175/1520-0493(1994)122<2573: AGMFTA $>2.0 . \mathrm{CO} ; 2$.

- 1995: Feature tracking on the unit sphere. Mon. Wea. Rev., 123, 3458-3465, https://doi.org/10.1175/1520-0493(1995) $123<3458$ :FTOTUS $>2.0$. CO; 2 .

Holton, J. R., and H.-C. Tan, 1980: The influence of the equatorial quasi-biennial oscillation on the global circulation at $50 \mathrm{mb}$. J. Atmos. Sci., 37, 2200-2208, https://doi.org/10.1175/15200469(1980)037<2200:TIOTEQ>2.0.CO;2.

Kiladis, G. N., and K. M. Weickmann, 1992: Circulation anomalies associated with tropical convection during northern winter. Mon. Wea. Rev., 120, 1900-1923, https://doi.org/10.1175/15200493(1992) $120<1900:$ CAAWTC $>2.0 . C O ; 2$.

Knapp, K. R., S. Applequist, H. J. Diamond, J. P. Kossin, M. Kruk, and C. Schreck, 2010a: NCDC International Best Track Archive for Climate Stewardship (IBTrACS) project, version 3.7. NOAA National Centers for Environmental Information, accessed 13 January 2016, https://doi.org/10.7289/V5NK3BZP.

- M. C. Kruk, D. H. Levinson, H. J. Diamond, and C. J. Neumann, 2010b: The International Best Track Archive for Climate Stewardship (IBTrACS). Bull. Amer. Meteor. Soc., 91, 363-376, https://doi.org/10.1175/2009BAMS2755.1.

Kocin, P. J., P. N. Schumacher, R. F. Morales Jr., and L. W. Uccellini, 1995: Overview of the 12-14 March 1993 superstorm. Bull. Amer. Meteor. Soc., 76, 165-182, https://doi.org/ 10.1175/1520-0477(1995)076<0165:OOTMS >2.0.CO;2.

Labitzke, K., and H. V. Loon, 1989: Association between the 11-yr solar cycle, the QBO, and the atmosphere. Part III: Aspects of the association. J. Climate, 2, 554-565, https://doi.org/10.1175/ 1520-0442(1989)002<0554:ABTYSC >2.0.CO;2.
L'Heureux, M. L., and R. W. Higgins, 2008: Boreal winter links between the Madden-Julian Oscillation and the Arctic Oscillation. J. Climate, 21, 3040-3049, https://doi.org/10.1175/ 2007JCLI1955.1.

Lim, E.-P., and I. Simmonds, 2002: Explosive cyclone development in the Southern Hemisphere and a comparison with Northern Hemisphere events. Mon. Wea. Rev., 130, 2188-2209, https:// doi.org/10.1175/1520-0493(2002)130<2188:ECDITS >2.0.CO;2.

Lupo, A. R., and P. J. Smith, 1995: Climatological features of blocking anticyclones in the Northern Hemisphere. Tellus, 47A, 439-456, https://doi.org/10.3402/tellusa.v47i4.11527.

Madden, R. A., and P. R. Julian, 1971: Detection of a 40-50 day oscillation in the zonal wind in the tropical Pacific. J. Atmos. Sci., 28, 702-708, https://doi.org/10.1175/1520-0469(1971) 028<0702:DOADOI $>2.0 . \mathrm{CO} ; 2$.

Martius, O., L. M. Polvani, and H. C. Davies, 2009: Blocking precursors to stratospheric sudden warming events. Geophys. Res. Lett., 36, L14806, https://doi.org/10.1029/2009GL038776.

Masato, G., B. J. Hoskins, and T. Woollings, 2013: Wave-breaking characteristics of Northern Hemisphere winter blocking: A two-dimensional approach. J. Climate, 26, 4535-4549, https:// doi.org/10.1175/JCLI-D-12-00240.1.

Matthews, A. J., B. J. Hoskins, and M. Masutani, 2004: The global response to tropical heating in the Madden-Julian oscillation during the northern winter. Quart. J. Roy. Meteor. Soc., 130, 1991-2011, https://doi.org/10.1256/qj.02.123.

Nakamura, H., and J. M. Wallace, 1990: Observed changes in baroclinic wave activity during the life cycles of low-frequency circulation anomalies. J. Atmos. Sci., 47, 1100-1116, https:// doi.org/10.1175/1520-0469(1990)047<1100:OCIBWA > 2.0.CO;2.

Pantillon, F., J.-P. Chaboureau, and E. Richard, 2015: Remote impact of North Atlantic hurricanes on the Mediterranean during episodes of intense rainfall in autumn 2012. Quart. J. Roy. Meteor. Soc., 141, 967-978, https://doi.org/10.1002/qj.2419.

Pelly, J. L., and B. J. Hoskins, 2003: A new perspective on blocking. J. Atmos. Sci., 60, 743-755, https://doi.org/10.1175/1520-0469 (2003)060<0743:ANPOB > 2.0.CO;2.

Renwick, J. A., and J. M. Wallace, 1996: Relationships between North Pacific wintertime blocking, El Niño, and the PNA pattern. Mon. Wea. Rev., 124, 2071-2076, https://doi.org/ 10.1175/1520-0493(1996)124<2071:RBNPWB >2.0.CO;2.

Rex, D. F., 1950: Blocking action in the middle troposphere and its effect upon regional climate. I. An aerological study of blocking action. Tellus, 2, 196-211, https://doi.org/10.1111/ j.2153-3490.1950.tb00331.x.

Riemer, M. S., C. Jones, and C. A. Davis, 2008: The impact of extratropical transition on the downstream flow: An idealized modeling study with a straight jet. Quart. J. Roy. Meteor. Soc., 134, 69-91, https://doi.org/10.1002/qj.189.

Rienecker, M. M., and Coauthors, 2011: MERRA: NASA's Modern-Era Retrospective Analysis for Research and Applications. J. Climate, 24, 3624-3648, https://doi.org/10.1175/ JCLI-D-11-00015.1.

Roebber, P. J., 1984: Statistical analysis and updated climatology of explosive cyclones. Mon. Wea. Rev., 112, 1577-1589, https:// doi.org/10.1175/1520-0493(1984)112<1577:SAAUCO > 2.0.CO;2.

Ropelewski, C. F., and M. S. Halpert, 1986: North American precipitation and temperature patterns associated with the El Niño/Southern Oscillation (ENSO). Mon. Wea. Rev., 114, 2352-2362, https://doi.org/10.1175/1520-0493(1986)114<2352: NAPATP $>2.0 . \mathrm{CO} ; 2$.

Rui, H., and B. Wang, 1990: Development characteristics and dynamic structure of tropical intraseasonal convection anomalies. 
J. Atmos. Sci., 47, 357-379, https://doi.org/10.1175/1520-0469(1990) 047<0357:DCADSO > 2.0.CO;2.

Salby, M. L., and H. H. Hendon, 1994: Intraseasonal behavior of clouds, temperature, and motion in the tropics. J. Atmos. Sci., 51, 2207-2224, https://doi.org/10.1175/1520-0469(1994)051<2207: IBOCTA $>2.0 . \mathrm{CO} ; 2$.

Sanders, F., and J. R. Gyakum, 1980: Synoptic-dynamic climatology of the "bomb." Mon. Wea. Rev., 108, 1589-1606, https:// doi.org/10.1175/1520-0493(1980)108<1589:SDCOT>2.0.CO;2.

Schwierz, C., M. Croci-Maspoli, and H. C. Davies, 2004: Perspicacious indicators of atmospheric blocking. Geophys. Res. Lett., 31, L06125, https://doi.org/10.1029/2003GL019341.

Thompson, D. B., and P. E. Roundy, 2013: The relationship between the Madden-Julian oscillation and U.S. violent tornado outbreaks in the spring. Mon. Wea. Rev., 141, 2087-2095, https://doi.org/10.1175/MWR-D-12-00173.1.

Tibaldi, S., and F. Molteni, 1990: On the operational predictability of blocking. Tellus, 42A, 343-365, https://doi.org/10.3402/ tellusa.v42i3.11882.

Tinsley, B. A., 1988: The solar cyclone and the QBO influences on the latitude of storm tracks in the North Atlantic. Geophys. Res. Lett., 15, 409-412, https://doi.org/10.1029/GL015i005p00409.

Torn, R. D., and G. J. Hakim, 2015: Comparison of wave packets associated with extratropical transition and winter cyclones. Mon. Wea. Rev., 143, 1782-1803, https://doi.org/10.1175/ MWR-D-14-00006.1.
Trenberth, K. E., G. W. Branstator, D. Karoly, A. Kumar, N. Lau, and C. Ropelewski, 1998: Progress during TOGA in understanding and modeling global teleconnections associated with tropical sea surface temperatures. J. Geophys. Res., 103, 14 291-14324, https://doi.org/10.1029/97JC01444.

Wang, C., and P.C. Fiedler, 2006: ENSO variability and the eastern tropical Pacific: A review. Prog. Oceanogr., 69, 239-266, https://doi.org/10.1016/j.pocean.2006.03.004.

Wang, J., H.-M. Kim, E. K. M. Chang, and S.-W. Son, 2018: Modulation of the MJO and North Pacific storm track relationship by the QBO. J. Geophys. Res. Atmos., 123, 39763992, https://doi.org/10.1029/2017JD027977.

Wheeler, M. C., and H. H. Hendon, 2004: An all-season real-time multivariate MJO index: Development of an index for monitoring and prediction. Mon. Wea. Rev., 132, 1917-1932, https:// doi.org/10.1175/1520-0493(2004)132<1917:AARMMI>2.0.CO;2.

Wiedenmann, J. M., A. R. Lupo, I. I. Mokhov, and E. A Tikhonova, 2002: The climatology of blocking anticyclones for the Northern and Southern Hemispheres: Block intensity as a diagnostic. J. Climate, 15, 3459-3473, https://doi.org/10.1175/ 1520-0442(2002)015<3459:TCOBAF $>2.0$. CO;2.

Wood, K. M., and E. A. Ritchie, 2014: A 40-year climatology of extratropical transition in the eastern North Pacific. J. Climate, 27, 5999-6015, https://doi.org/10.1175/JCLI-D-13-00645.1.

Zhang, C., 2005: Madden-Julian Oscillation. Rev. Geophys., 43, RG2003, https://doi.org/10.1029/2004RG000158. 